\title{
Highlights:
}

Ru/Al-MCM-48 exhibited higher activity than most catalytic systems reported High temperature and pressure enhance the production of hexitols.

Cellobitol was the main intermediate in the conversion of cellobiose to hexitols Development of kinetic model for the catalytic conversion of cellobiose to sorbitol. Hydrolysis of cellobitol to sorbitol is the rate-determining step. 
Graphical abstract

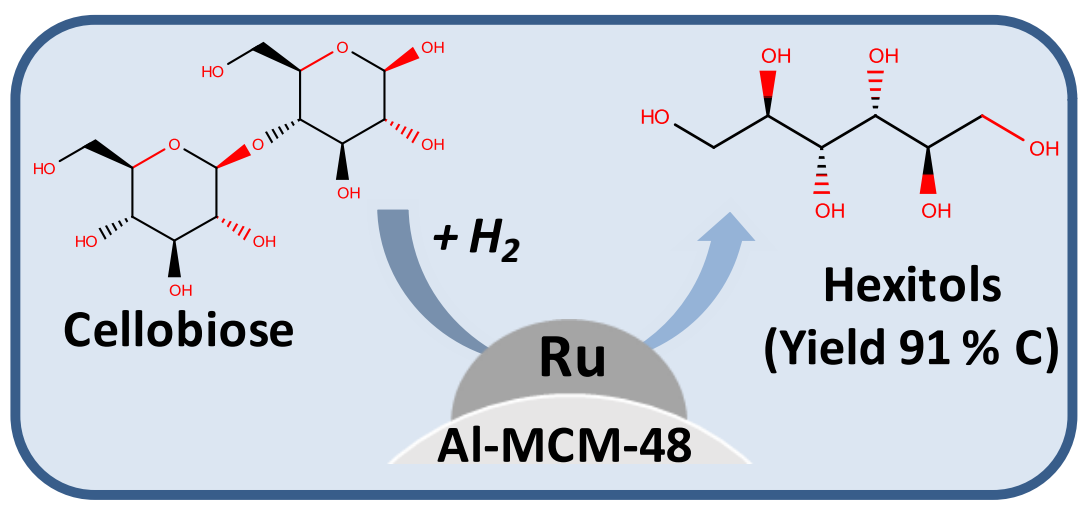




\section{One-pot catalytic hydrolysis/hydrogenation of cellobiose into hexitols over Ru/Al-MCM-48}

A. Romero ${ }^{\text {a }}$ J. A. Díaz ${ }^{\text {, A. Nieto-Márquez }}{ }^{\text {** }}$, N. Essayem ${ }^{\text {d }}$, E. Alonso ${ }^{\text {a }}$, C. Pinel $^{\mathrm{d}}$

${ }^{a}$ High Pressure Processes Group. - Chemical Engineering and Environmental Technology Department - Dr. Mergelina s/n, 47011 Valladolid, Spain.

b Catalonia Institute for Energy Research, Jardins de les Dones de Negre, 12 Pl Sant Adria de Besòs 08930, Spain

${ }^{c}$ Mechanical, Chemical and Industrial Design Engineering Department. - Technical University of Madrid (UPM). Ronda de Valencia 3, 28012 Madrid, Spain.

d Université Lyon, CNRS, Université Claude Bernard Lyon 1, IRCELYON, UMR 5256, F69626, Villeurbanne, France.

*Corresponding author: antonio.nieto@upm.es 


\begin{abstract}
The simultaneous catalytic hydrolysis and hydrogenation of cellobiose, as a model constituent of biomass has been studied over Ru/Al-MCM-48. The catalyst, presenting both acidic and hydrogenating functions has been synthesized and characterized by means of $\mathrm{N}_{2}$ adsorptiondesorption, SAXS, $\mathrm{H}_{2}-\mathrm{TPR}, \mathrm{XRD}$, TEM and $\mathrm{NH}_{3}$-TPD. A kinetic model is proposed, and possible reaction pathways and key intermediate compounds of conversion of cellobiose to hexitols are discussed. In the kinetic study the effects of pressure, temperature and time on the one-pot reaction were evaluated. A maximum yield around $91 \%$ of hexitols was achieved at 180 ${ }^{\circ} \mathrm{C}, 5 \mathrm{MPa}$ of $\mathrm{H}_{2}$ and $7 \mathrm{~min}$, where sorbitol was the main compound in the final product with 82 $\%$ yield. Cellobitol was the main reaction intermediate. Temperatures in the range of $140-180$ ${ }^{\circ} \mathrm{C}$ and pressures in the range of $3-5 \mathrm{MPa}$ of $\mathrm{H}_{2}$ were studied and it was concluded that higher temperatures and pressures had a positive effect in order to maximize the production of hexitols. The developed kinetic model predicted with high accuracy the concentration of the different compounds involved in the proposed reaction pathway and served to calculate the specific reaction rate and activation energy values for the different steps of the catalytic process.
\end{abstract}

\title{
KEYWORDS
}

Ru/Al-MCM-48, Cellobiose, Hexitols, Hydrolysis/Hydrogenation, Sorbitol 


\section{Introduction}

Nowadays, the high energy demand, problems derived from global warming and the diminishing of fossil fuel reserves, have encouraged the scientific community to look for alternative raw materials for the production of fuels and chemicals, as well as the development of new renewable energy sources [1-4]. These alternatives should meet the two following requirements: a) to be renewable and b) to be potentially sustainable [5]. Lignocellulosic biomass is constituted by three structural polymers, namely cellulose $(34-50 \%)$, hemicelluloses $(19-$ $34 \%)$ and lignin $(11-30 \%)$ [6]. Cellulose is the most abundant source of biomass on earth and it is currently considered as a potential alternative carbon source to fossil fuels for the sustainable production of chemicals and fuels [7]. Nevertheless, according to both complex crystalline structure -composed by $\beta$-1,4-glycosidic bonds of D-Glucose- and its insolubility in conventional solvents, cellulose conversion still remains as a technological challenge. Thus, the development of bifunctional acid/redox catalysts for the efficient valorization of cellulose towards highly valuable chemicals such as sugar alcohols, glycols and alkanes, is extremely necessary [8-10].

Great attention have been paid to conversion of cellulosic biomass into hexitols such as sorbitol, which is a sugar alcohol with a wide range of uses in food, pharmaceutical, cosmetics and industrial applications [11]. Additionally, sorbitol is a platform chemical of considerable importance for the production of useful chemicals such as isosorbide, 1,4-sorbitan or alkanes [12]. Considering production of chemicals, polyols show some advantages over fossil sources: a) High atom economy since during conversion process most of the hydroxyl groups from cellulose are preserved in the desired polyol, b) good economic viability according to the high value of polyols and c) market capacity of polyols is noteworthy (30 - 40 million ton/year) but not too 
large [13]. In general terms, hydrolytic conversion of cellulose to sorbitol comprises two successive steps: a) Cellulose depolymerization into monosaccharides such as D-Glucose, which has been promoted by enzymes [14, 15], liquid acids [16], solid acids [17] and supercritical water [18] and b) further hydrogenation of so obtained soluble sugars to sorbitol in the presence of active metals under hydrogen atmosphere $[19,20]$. In the recent years, one-pot catalytic hydrolysis/hydrogenation of cellulose to sorbitol has been develop, being the objective of several studies [1,21, 22]. It is still a challenge to develop kinetic studies from cellulose according to its complex structure. As an approach, simple model compounds such as cellobiose, which represents the basic repeating unit of cellulose consisting of two glucose monomers, has been used for this purpose, being the pioneering work the reported by Yan et al. [23].

Negahdar et al. carried out kinetic tests for the hydrolytic hydrogenation of cellobiose to sorbitol using a catalytic system consisting of silicotungstic acid and a supported ruthenium catalyst $(5 \mathrm{wt} . \% \mathrm{Ru} / \mathrm{C})$ [24]. They found two competitive reaction pathways for hydrolytic hydrogenation of cellobiose: a) First pathway consisting on the hydrolysis of cellobiose towards D-Glucose and the subsequently hydrogenation of D-Glucose to sorbitol and b) a secondary reaction route where cellobiose is hydrogenated to 3-D-glucopyranosyl-D-glucitol (also known as cellobitol), which is further hydrolyzed to sorbitol. In this second route D-Glucose can also be obtained as intermediate of cellobitol hydrolysis. Conversion of cellobiose to sorbitol was also studied over Ru deposited on zirconia-modified SBA-15 [25], Ru deposited on carbon nanotubes [26], a combination of $\mathrm{H}_{3} \mathrm{PO}_{4}+\mathrm{Ru} / \mathrm{C}$ [27] and combinations of molten salts hydrate $\mathrm{ZnCl}_{2} \cdot 4 \mathrm{H}_{2} \mathrm{O}$ $+\mathrm{Ru} / \mathrm{C}[28]$.

In the present work, we report the catalytic performance of bifunctional Ru/Al-MCM-48 in the hydrolytic hydrogenation of cellobiose into sorbitol. Up to our knowledge, this is the first work 
that uses MCM-48 type materials for the catalytic hydrolysis/hydrogenation of cellobiose, that has been previously demonstrated to present a very good response in other biomass transformations $[8,9,29]$. The interesting textural properties of Al-MCM-48 avoid diffusional limitations of large molecules [30], and the presence of aluminum increases the number of acid sites compared to MCM-48 and these features play a significant role for hydrolysis steps involved in the conversion of cellobiose to sorbitol. Results obtained show a higher intrinsic activity than the previously reported in the literature in almost all the cases found, even without the addition of homogeneous or heteropolyacids. In addition, a kinetic model covering different reaction temperatures was developed and the possible reaction mechanisms, depending on the experimental conditions, are also discussed.

\section{Materials and methods}

\subsection{Catalyst preparation}

Synthesis of Al-MCM-48 has been done by the standard hydrothermal sol-gel method, as described in a previous work [9]. In a conventional synthesis, n-Hexadecyl-trimethylammonium bromide $\left(\mathrm{CH}_{3}\left(\mathrm{CH}_{2}\right)_{15} \mathrm{~N}(\mathrm{Br})\left(\mathrm{CH}_{3}\right)_{3} \geq 98 \%\right.$, Sigma - Aldrich), which acts as template, was dissolved in the mixed solution of $42 \mathrm{~cm}^{3}$ of distilled water, $13 \mathrm{~cm}^{3}$ of aqueous ammonia $(20 \%$ as $\mathrm{NH}_{3}$, Panreac), $18 \mathrm{~cm}^{3}$ of absolute ethanol (partially denaturated QP, Panreac) and $0.077 \mathrm{~g}$ of sodium aluminate $\left(\mathrm{NaAlO}_{2}\right.$, Sigma - Aldrich), related to a ratio $\mathrm{Si} / \mathrm{Al}=20$, by stirring for 15 min. After that, $4 \mathrm{~cm}^{3}$ of TEOS ( $\geq 99 \%$ GC, Sigma - Aldrich) were added dropwise. The final solution was stirred for $18 \mathrm{~h}$ in a hydrothermal bath; the white precipitates were collected by vacuum filtration and washed with distilled water until $\mathrm{pH}=7$. Then, precipitates were dried at 
$60{ }^{\circ} \mathrm{C}$ overnight. Dried precipitates were calcined with air from $80{ }^{\circ} \mathrm{C}$ to $550{ }^{\circ} \mathrm{C}$ (heating rate of 2

${ }^{\circ} \mathrm{C} \cdot \min ^{-1}$ ) and kept at the final temperature overnight.

Ruthenium was deposited on Al-MCM-48, with a metal loading around $4 \%$, by using the conventional wet impregnation method (WI). Ruthenium (III) chloride anhydrous (supplied by Strem Chemicals Inc.) was used as metal precursor for this preparation. The desired amounts of the metal salt and $2 \mathrm{~g}$ support were sonicated in water $(20 \mathrm{~mL}$ and $40 \mathrm{~mL}$, respectively) for 10 min, separately. Then, the resulting ruthenium trichloride solution and Al-MCM-48 dispersion in water were mixed and heated up from room temperature to $105^{\circ} \mathrm{C}$ (heating rate of $1{ }^{\circ} \mathrm{C} \cdot \min -1$ ) using a Stuart model SD162 heating plate. The impregnation process finishes when water is completely evaporated; then, the final product is dried at $105{ }^{\circ} \mathrm{C}$ overnight. After that, the material is milled and reduced at $150^{\circ} \mathrm{C}$ under hydrogen atmosphere for $1 \mathrm{~h}$.

\subsection{Catalyst characterization}

Small Angle X-Ray Scattering (SAXS) and X-Ray Diffraction (XRD) were performed in a Bruker Discover D8 Focus diffractometer using the $\mathrm{Cu} \mathrm{K} \alpha$ radiation $(\lambda=0.15406 \mathrm{~nm})$. The diffraction intensities were measured, for XRD, over an angular range of $20^{\circ}<2 \theta<90^{\circ}$ with a step size of $0.03^{\circ}$ and a count time of $2 \mathrm{~s}$ per step. In case of SAXS, $2^{\circ}<2 \theta<6^{\circ}$ was selected as angular range with a step size of $0.02^{\circ}$ and a count time of $1 \mathrm{~s}$ per step.

Nitrogen adsorption-desorption at $-196^{\circ} \mathrm{C}$ was performed with ASAP 2020 (Micromeritics) to obtain surface and pore properties of Al-MCM-48 and Ru/Al-MCM-48. Prior to analysis, the samples were outgassed overnight at $350{ }^{\circ} \mathrm{C}$. Total specific surface areas were determined by the multipoint BET method at $P / P_{0} \leq 0.3$, total specific pore volumes were evaluated by single point adsorption of $\mathrm{N}_{2} P / P_{0} \geq 0.99$. Pore diameter was obtained by $\mathrm{BJH}$ adsorption average $\left(4 \cdot \mathrm{V} \cdot \mathrm{A}^{-1}\right.$, 
$\mathrm{nm}$ ). Pore size distribution was derived from the adsorption branch of the isotherm by BJH (dV/dD), Halsey: Faas correction.

Temperature Programmed Reduction ( $\left.\mathrm{H}_{2}-\mathrm{TPR}\right)$ profile of $\mathrm{Ru} / \mathrm{Al}-\mathrm{MCM}-48$ was recorded using the commercial Micromeritics TPD/TPR 2900 unit. The sample was loaded into a U-shaped quartz cell $(100 \mathrm{~mm} \times 3.76 \mathrm{~mm}$ i.d. $)$, ramped $\left(10^{\circ} \mathrm{C} \cdot \mathrm{min}^{-1}\right)$ from room temperature to $800{ }^{\circ} \mathrm{C}$ under a flow of $\mathrm{H}_{2} / \mathrm{N}_{2}\left(5 \% \mathrm{v} / \mathrm{v} ; 50 \mathrm{~cm}^{3} \cdot \mathrm{min}^{-1}\right.$, Air Liquide $)$ and kept at the final temperature until the signal returned to the baseline. Hydrogen consumption was monitored by a thermal conductivity detector (TCD) with data acquisition/manipulation using the ChemiSoft TPX V1.03 ${ }^{\mathrm{TM}}$ software.

$\mathrm{NH}_{3}$-TPD experiments were performed in the same analyzer. In this case, the samples were activated under $\mathrm{H}_{2}$-TPR conditions $\left(150{ }^{\circ} \mathrm{C}\right)$ for $60 \mathrm{~min}$ and then they were saturated with ammonia at $100{ }^{\circ} \mathrm{C}$ during $30 \mathrm{~min}$. $\mathrm{NH}_{3}$ was purged using pure $\mathrm{He}$ during 60 min and then samples were heated from $100{ }^{\circ} \mathrm{C}$ to $600{ }^{\circ} \mathrm{C}$ (ramped $15^{\circ} \mathrm{C} \cdot \mathrm{min}^{-1}$ ) and $\mathrm{kept}$ at the final temperature until the signal returned to the baseline. The amount of chemisorbed ammonia was calculated according to calibrated volumes of this compound.

Transmission electron microscopy (TEM) analyses used a JEOL 2100 unit with an accelerating voltage of $200 \mathrm{kV}$. Ru/Al-MCM-48 was prepared by ultrasonic dispersion in acetone with a drop of the resultant suspension, which was evaporated onto a holey carbon-supported grid. A counting of ruthenium nanoparticles was carried out from TEM images of Ru/Al-MCM-48. 175 ruthenium nanoparticles were counted and the mean Ru particle size was expressed as surfacearea weighted diameter $\left(\overline{\mathrm{d}}_{\mathrm{s}}\right)$, which was calculated from the following equation (Eq. 1) [31].

$$
\bar{d}_{s}=\frac{\sum_{i} n_{i} \cdot d_{i}^{3}}{\sum_{i} n_{i} \cdot d_{i}^{2}}
$$

In equation $1, n_{i}$ is the number of ruthenium nanoparticles with a diameter $d_{i}$. 
Ruthenium loading in Ru/Al-MCM-48 was determined by means of atomic absorption (AA) spectrophotometry, using a SPECTRA 220FS analyzer. Approximately, $0.05 \mathrm{~g}$ of the sample, 3 $\mathrm{mL}$ of $\mathrm{HCl}, 3 \mathrm{~mL} \mathrm{H}_{2} \mathrm{O}_{2}$ and $3 \mathrm{~mL} \mathrm{HF}$ were treated by microwave digestion at $250{ }^{\circ} \mathrm{C}$ and the final solution was measured in the spectrophotometer.

\subsection{Catalytic tests}

In a typical catalytic experiment, $2 \mathrm{~g}$ of cellobiose (for microbiology, $\geq 99.0 \%$, supplied by Sigma-Aldrich) were dissolved in $50 \mathrm{~mL}$ of distilled water. Then, the final solution of cellobiose (concentration of $40 \mathrm{~g} \cdot \mathrm{l}^{-1}$ ) and $0.5 \mathrm{~g}$ of catalyst were added into a $200 \mathrm{~mL}$ stainless steel batch reactor PID controlled. The internal wall of the reactor is protected by a Teflon vessel in order to prevent corrosion. The reactor was flushed with $\mathrm{N}_{2}$ and pressurized with a low pressure of 0.5 $\mathrm{MPa}$ of $\mathrm{N}_{2}$. The reaction mixture was stirred at $1200 \mathrm{rpm}$ and heated up to the desired temperature at an average rate of $6^{\circ} \mathrm{C} \cdot \mathrm{min}^{-1}$. Temperature ranged from $140^{\circ} \mathrm{C}$ to $180^{\circ} \mathrm{C}$. When the reactor reached the reaction temperature, it was pressurized at $5 \mathrm{MPa}$ of $\mathrm{H}_{2}$ and it was considered as $\mathrm{t}=0 \mathrm{~min}$. Lower pressures of hydrogen were also tested in this work (4 and 3 $\mathrm{MPa}$ ). The reactor had a sampling valve in order to obtain samples from the aqueous phase at different reaction times. At the end of the experiment, the reactor was cooled down in an ice bath to rapidly stop the reaction. Then, it was depressurized and opened. Samples from aqueous phase were analyzed by means of total organic carbon (TOC, $\mathrm{mg} \cdot \mathrm{l}^{-1} \mathrm{C}$ ) using a Shimadzu TOC-VCSH analyzer and High Performance Liquid Chromatography (HPLC). The HPLC column used was a SUPELCO $\mathrm{Ca}^{2+}$ from Supelco at $60{ }^{\circ} \mathrm{C}$ and a flow of $0.4 \mathrm{~cm}^{3} \cdot \mathrm{min}^{-1}$ using water Milli-Q as the mobile phase. A Shimadzu refractive index detector (IR) was used to identify sugars, polyols and their derivatives. Cellobiose conversion and yield to the reaction products were calculated using 
equations 2 and 3, taking into account the reaction stoichiometry. Concentrations of all the compounds involved in the calculation are expressed in carbon basis.

$$
\begin{aligned}
& X_{\text {Cellobiose }}(\%)=\frac{[\text { Cellobiose }]_{0}-[\text { Cellobiose }]_{f}}{[\text { Cellobiose }]_{0}} \cdot 100 \\
& Y_{\text {product }}(\%)=\frac{[\text { Product }]}{[\text { Cellobiose }]_{0}} \cdot 100 \\
& \text { Specific reaction rate }=\frac{n_{\text {sorbitol }}}{n_{R u} \cdot t}
\end{aligned}
$$

\section{Results and discussion}

\subsection{Catalyst and support characterization}

Figure 1 shows Small Angle X-Ray Scattering (SAXS) pattern of Al-MCM-48. Calcined AlMCM-48 shown four main Bragg diffraction peaks in the $2 \theta$ range from $2-5^{\circ}$, that can be assigned to (211), (220), (420) and (332) planes. These results demonstrated the high quality of mesoporous Al-MCM-48, where the cubic phase belongs to a Ia3d space group symmetry [32, 33]. The $d_{220}$ and $d_{211}$ reflections were observed at approximately $2 \theta$ values of 2.6 and 3 , respectively. The calculation of the ratio $d_{220} / d_{211}$ for Al-MCM-48 was 0.86 , which is typical of cubic symmetry [32-34].

Adsorption-desorption isotherms of $\mathrm{N}_{2}$ at $-196{ }^{\circ} \mathrm{C}$ were determined in order to study textural properties of Al-MCM-48 and Ru/Al-MCM-48 and results are presented in Figure 2 and Table 1. It is observed that in both cases, the materials presented isotherms that can be ascribed to type IV, according the IUPAC classification [35] and consistent with mesoporous solids, with a sharp increase in quantity adsorbed at approximately relative pressures $\left(P / P_{0}\right)$ between 0.15 and 0.3 . This fact is associated with capillary condensation in the mesostructured channels of Al-MCM48. Capillary condensation phenomenon is typical from mesoporous materials and it is indicative 
of the uniformity of the porous structure [36]. This was confirmed in pore size distribution in Figure 2, where both Al-MCM-48 and Ru/Al-MCM-48 shown unimodal and narrow pore size distributions centered at approximately $20 \AA$. Moreover, it was observed that both samples exhibit a very narrow type- $\mathrm{H} 3$ hysteresis loop at $P / P_{0}=0.45-0.9$, which can be associated to the particular and three-dimensional pore structure of this kind of materials. Bet surface area and total pore volume of Al-MCM-48 were $1352 \mathrm{~m}^{2} \cdot \mathrm{g}^{-1}$ and $0.81 \mathrm{~cm}^{3} \cdot \mathrm{g}^{-1}$, respectively. Similar results were obtained for Al-MCM-48 by Meng et al [37]. A slight decrease in the specific surface area and pore volume of Ru/Al-MCM-48 are noticed after the deposition of ruthenium into the pores of Al-MCM-48, from 1352 to $1028 \mathrm{~m}^{2} \cdot \mathrm{g}^{-1}$ and from 0.81 to $0.57 \mathrm{~cm}^{3} \cdot \mathrm{g}^{-1}$, respectively. This fact is associated to the partial blocking of the mesoporous network of the AlMCM-48. The alteration of the pore diameter from 2.5 to $2.7 \mathrm{~nm}$ upon $\mathrm{Ru}$ introduction can be ascribed to a slight damage in the mesopore system of Al-MCM-48. The ruthenium metal loading of Ru/Al-MCM-48 was $3.5 \%$, determined by AA. Regarding acidity of the prepared materials, Al-MCM-48 and Ru/Al-MCM-48 shown 0.842 and $1.219 \mathrm{mmol}_{\mathrm{NH} 3} \cdot \mathrm{g}^{-1}$, determined by TPD-NH $\mathrm{N}_{3}$. Acidity value of Al-MCM-48 is attributed to the presence of weak acid hydroxyl groups and tri-coordinated aluminum in the mesoporous framework [37]. Then, after the deposition of ruthenium into the pores of Al-MCM-48, a noticeable increase ammonia uptake was detected in Ru/Al-MCM-48. This observation can be associated to the high tendency of ruthenium atoms to adsorb ammonia [38], while the influence of chlorine atoms cannot be discarded (no calcination was done after impregnation).

$\mathrm{H}_{2}$-TPR profile for Ru/Al-MCM-48 is shown in Figure 3(A), in order to discuss the reducibility of the different ruthenium species present on Al-MCM-48. $\mathrm{H}_{2}$-TPR profile exhibits two reduction peaks at ca. $135^{\circ} \mathrm{C}$ and $175^{\circ} \mathrm{C}$ for Ru/Al-MCM-48. 
The reduction of $\mathrm{Ru}$-using $\mathrm{RuCl}_{3}$ as precursor- over mesoporous silica and other materials (activated carbon, $\mathrm{TiO}_{2}$ ) without a previous calcination step has been widely reported in the literature $[8,9,39]$. It is well accepted that the reduction takes place through a main hydrogen consumption within $150-250{ }^{\circ} \mathrm{C}$, corresponding to the reduction of the $\mathrm{Ru}^{3+}$ species present in the salt. When this peak splits into two, it is attributed to the location of Ru species in different environments. Here, as will be commented below based on TEM images, Ru nanoparticles were present both as big conglomerations in the outer surface of the Al-MCM-48 particles and finely dispersed within the pores. These two different environments must account for different reduction temperatures. According to the $\mathrm{H}_{2}$-TPR profile, $\mathrm{Ru} / \mathrm{Al}-\mathrm{MCM}-48$ was activated at 150 ${ }^{\circ} \mathrm{C}$ under hydrogen atmosphere for $1 \mathrm{~h}$ in order to assure the proper reduction of all the ruthenium species.

XRD patterns for the bare support, $\mathrm{Ru} / \mathrm{Al}-\mathrm{MCM}-48$ before reduction and Ru/Al-MCM-48 after reduction are shown in Figure 3(B). No diffraction peaks were observed at the range of $2 \theta$ from $30^{\circ}$ to $80^{\circ}$ for Al-MCM-48 and Ru/Al-MCM-48 before reduction, as expected. After the reduction under hydrogen atmosphere, a broad metallic diffraction peak related to $\mathrm{Ru}^{0}(101)$ was observed at $2 \theta=43.8^{\circ}$ for $\mathrm{Ru} / \mathrm{Al}-\mathrm{MCM}-48$, corresponding to the presence of Hexagonal Close Packing $(\mathrm{HCP}) \mathrm{Ru}^{0}$ nanoparticles. This fact confirms the correct reduction of $\mathrm{Ru} / \mathrm{Al}-\mathrm{MCM}-48$ (Figure 3(B)). In addition, the small and wide metallic ruthenium peak suggests the existence of small $\mathrm{Ru}^{0}$ nanoparticles well-distributed into the porous structure of Al-MCM-48. This fact is in good agreement with the calculations based on Scherrer equation, which determined the presence of $\mathrm{Ru}^{0}$ nanoparticles with a crystallite size of $1.9 \mathrm{~nm}$. 
TEM-images and ruthenium nanoparticle size distribution for Ru/Al-MCM-48 are presented in Figure 4. Two different areas were observed by TEM for Ru/Al-MCM-48: a) Regions where ruthenium nanoparticles are finely distributed into the pores of Al-MCM-48 (Figure 4(A)) and b) other areas where agglomerates of ruthenium nanoparticles were detected in the outer surface of the support (Figure 4(B)). This fact confirms a correlation between TEM images and reduction peaks from $\mathrm{H}_{2}$-TPR, where the ruthenium agglomerates present in the outer surface of Al-MCM48 are related to the reduction peak at lower temperature in $\mathrm{H}_{2}$-TPR, while the well-distributed ruthenium nanoparticles are associated to the second reduction peak observed at higher temperatures. In addition, a counting of ruthenium nanoparticles (excluding the global size of the agglomerates) from TEM-images was developed and the ruthenium nanoparticle size distribution is presented in Figure 4(C). The histogram showed a narrow ruthenium nanoparticle size distribution in the range $1.2-2.5 \mathrm{~nm}$, consistent with the calculated by XRD. Surface-area weighted diameter of $2.0 \mathrm{~nm}$ was obtained from calculations based on equation (1).

\subsection{Catalytic hydrolysis/hydrogenation of cellobiose}

The catalytic performance of $\mathrm{Ru} / \mathrm{Al}-\mathrm{MCM}$-is tested at different experimental conditions: temperature, pressure and reaction time, with the goal of maximizing the production of hexitols.

Concentration profiles during the conversion of cellobiose at $5 \mathrm{MPa}$ of $\mathrm{H}_{2}$ and temperatures between 140 and $180{ }^{\circ} \mathrm{C}$ are given in Figure 5. Conversions of cellobiose were $22 \%, 41 \%$ and $73 \%$ at $140{ }^{\circ} \mathrm{C}, 160^{\circ} \mathrm{C}$ and $180^{\circ} \mathrm{C}$ and 1 min of reaction time, respectively. Thus, the increase of reaction temperature from $140{ }^{\circ} \mathrm{C}$ to $180{ }^{\circ} \mathrm{C}$ resulted in an important increase of the conversion of cellobiose at the initial reaction stage, as expected. Total conversion of cellobiose was achieved after 20,10 and $5 \mathrm{~min}$, at $140^{\circ} \mathrm{C}, 160^{\circ} \mathrm{C}, 180^{\circ} \mathrm{C}$, respectively. In general terms, according to the 
results presented in Figure 5, cellobiose is rapidly hydrogenated to cellobitol which is further hydrolyzed into sorbitol. Therefore, cellobitol was the main reaction intermediate during cellobiose hydrolysis/hydrogenation over Ru/Al-MCM-48. No glucose issued from hydrolysis of cellobiose could be detected in any case. Nevertheless, hydrolysis of cellobiose into D-glucose cannot be discarded. Low amounts of D-glucose can be obtained, which are rapidly hydrogenated into sorbitol and due to this fact, D-glucose cannot be observed in the chromatograms. This fact was also reported by Deng et al [26], where only traces of D-glucose could be observed at the initial reaction stage using Ru/CNT as catalyst with lower ruthenium nanoparticle sizes than $12 \mathrm{~nm}$. The highest yields to cellobitol were reached around $82 \%, 48 \%$ and $34 \%$ at $140{ }^{\circ} \mathrm{C}, 160{ }^{\circ} \mathrm{C}$ and $180{ }^{\circ} \mathrm{C}$, respectively. The decrease in the maximum yield to cellobitol observed when temperature increases agrees with the previously reported in the literature [24]. Once that maximum yield to cellobitol was achieved at each temperature, it decreased as a result of the conversion of cellobitol to sorbitol. Then, consecutive isomerization processes of the so obtained sorbitol enhanced the production of mannitol and iditol. Other isomers, like allitol or dulcitol were not detected. Other byproducts from sorbitol dehydration such as 1,4-sorbitan and isosorbide were also detected in very low concentrations at temperatures higher than $140{ }^{\circ} \mathrm{C}$ (Figure 5B and 5C) [40]. Regardless, the temperature, the mass balance closed better than $98 \%$.

The influence of the temperature at $5 \mathrm{MPa}$ of $\mathrm{H}_{2}$ and after 5 min of reaction on the conversion of cellobiose and selectivity to hexitols is presented in Figure 6A. Conversion of cellobiose was around $52 \%$ at $140{ }^{\circ} \mathrm{C}$, achieving a yield to hexitols around $5 \%$. A yield of cellobitol around 47 $\%$ was detected in the final product. This low yield to hexitols is attributed to the high stability of the intermediate cellobitol at low temperatures. Conversion of cellobiose improved up to $92 \%$ 
by increasing the temperature at $160{ }^{\circ} \mathrm{C}$, and around $42 \%$ of hexitols were observed as a result of the hydrolysis of cellobitol. However an important yield to cellobitol -around $48 \%$-was still detected in the final product. Finally, total conversion of cellobiose was achieved at $180{ }^{\circ} \mathrm{C}$. A significant yield to hexitols of $87 \%$ was reached and $12.5 \%$ of cellobitol remained in the final product. According to all these results given in Figure 6A, it is possible to conclude that higher temperatures have a positive effect in order to maximize the yield to hexitols at a certain time, since more cellobitol can be hydrolyzed at higher temperatures. In all the cases, sorbitol was the more abundant hexitols in the final product, however; other products such as mannitol and iditol were observed at lower concentrations. Isomerization of sorbitol was favored at lower temperatures, thus lower yields to mannitol and iditol were observed when temperature increased. Results are also compared at the same (total) conversion level and given in Table 2. The maximum yield to hexitols, which was calculated as the sum of the yields of sorbitol, mannitol and iditol was around $89 \%$ at $140{ }^{\circ} \mathrm{C}$ and $240 \mathrm{~min}, 88 \%$ at $160{ }^{\circ} \mathrm{C}$ and $30 \mathrm{~min}$ and 91 $\%$ at $180^{\circ} \mathrm{C}$ and 7 min. In spite of obtaining a similar maximum of hexitols -between 88 and 91 $\%-$ at different temperatures, the composition of the final product was different. When temperature increases from $140{ }^{\circ} \mathrm{C}$ to $180{ }^{\circ} \mathrm{C}$, the maximum in the yield of hexitols was reached at lower reaction times (Table 2). The greater conversion of cellobitol at higher temperatures allowed to obtain higher yields to sorbitol and low reaction times avoided further transformation reactions of sorbitol. Thus, at higher temperatures and lower reaction times, the yield to sorbitol increased and the yield to mannitol and iditol decreased.

The influence of pressure of hydrogen in the range between 3 and $5 \mathrm{MPa}$ was also studied and the main results are presented in Figure 6B. Working within this pressure range did not demonstrate an important influence in terms of conversion. Conversion of cellobiose was around 
$99 \%$ at $3 \mathrm{MPa}$, while it was $100 \%$ at higher pressures. However, pressure had a big influence in the reaction pathway converting cellobiose to hexitols. At $3 \mathrm{MPa}$ of $\mathrm{H}_{2}$, glucose was the unique intermediate of the reaction, while cellobitol was not detected (Figure 7A). At $4 \mathrm{MPa}_{2}$, glucose was the main intermediate of the reaction, while only low amounts of cellobitol were detected (Figure 7B). However, working at $5 \mathrm{MPa}$ of $\mathrm{H}_{2}$ cellobitol was the main intermediate and glucose was not detected in the final product (Figure 7C). Therefore, it can be concluded that at pressures lower than $5 \mathrm{MPa}$, concentration of hydrogen is limiting hydrogenation of cellobiose to cellobitol enhancing hydrolysis of cellobiose to glucose, while at $5 \mathrm{MPa}$ of $\mathrm{H}_{2}$ hydrogenation of cellobiose to cellobitol is favored, avoiding hydrolysis of cellobiose to glucose. In general, higher hydrogen pressures demonstrated a significant influence promoting greater yields to hexitols. Yield to hexitols was $76 \%$ at $3 \mathrm{MPa}$ of $\mathrm{H}_{2}, 90 \%$ at $4 \mathrm{MPa}$ of $\mathrm{H}_{2}$ and $91 \%$ at $5 \mathrm{MPa}$ of $\mathrm{H}_{2}$ after 7 min of reaction time. The lower yield to hexitols obtained at $3 \mathrm{MPa}$ compared to those obtained at higher pressures, can be attributed to mass transfer limitations from gas to liquid phase. At lower pressures the availability of hydrogen in the reaction media is influencing the reaction mechanism. This fact is in good agreement with the experimental results reported by Negahdar et al [24]. They stated the effect of pressure in the catalytic conversion of cellobiose to sorbitol and according to their experimental results the authors concluded that a kinetic control of the reaction can be surely assumed at a stirring rate above $750 \mathrm{rpm}$ and pressure of hydrogen above $3.5 \mathrm{MPa}$ and low concentrations of cellobiose in the solution. Therefore, working at higher hydrogen pressures than 3.5 $\mathrm{MPa}$ under the presented experimental conditions in this work, hydrolysis/hydrogenation of cellobiose is not limited. Moreover, higher hydrogen pressures favored isomerization reactions of sorbitol to mannitol and iditol, increasing their yield in the final product. According to the aforementioned experimental results the optimal conditions for 
conversion of cellobiose to maximize the yield to hexitols $(91 \%)$ were selected at $180{ }^{\circ} \mathrm{C}, 7 \mathrm{~min}$ and $5 \mathrm{MPa}$ of $\mathrm{H}_{2}$.

Activity results obtained in this work are compared with those previously reported by other authors (Table 3). It is common to find many catalytic data in the literature in terms of yield to sorbitol. However, since the specific reaction rate is the most meaningful parameter in order to compare the catalytic activity of different materials, in addition to consider yield to sorbitol, specific reaction rate was also calculated in Table 3. Niu et al. reported the one-pot conversion of cellobiose to hexitols over $\mathrm{Ru}$ on SBA-15 [25]. In that work, a yield to sorbitol of $4 \%$ was achieved at $140{ }^{\circ} \mathrm{C}, 5 \mathrm{MPa}$ and $15 \mathrm{~min}$ over $\mathrm{Ru} / \mathrm{SBA}-15$ (1.7 wt. \%). Under the same experimental conditions Ru/Al-MCM-48 demonstrated a higher yield to sorbitol around $17 \%$. In addition, the specific reaction rate of Ru/Al-MCM-48 at $140{ }^{\circ} \mathrm{C}, 5 \mathrm{MPa}$ and 15 min was a $29 \%$ higher than that obtained by Ru/SBA-15. In the same work, Niu et al. tested a Ru on zirconiamodified SBA-15 (1.8 wt.\%), which showed a good catalytic behavior, achieving a yield to sorbitol of $15 \%$ at $140{ }^{\circ} \mathrm{C}, 5 \mathrm{MPa}$ and $15 \mathrm{~min}$, comparable to that obtained in this work under similar experimental conditions. Modification with $\mathrm{Zr}$ on SBA-15 improved the number of acid sites enhancing the production of sorbitol in comparison with Ru/SBA-15. Ru/Zr-SBA-15 revealed a specific reaction rate of $1.59 \mathrm{~mol}_{\text {Sorbitol }} \cdot \mathrm{mol}_{\mathrm{Ru}}{ }^{-1} \cdot \mathrm{min}^{-1}$, which is around 2.1 times higher than that obtained for Ru/Al-MCM-48 at $140{ }^{\circ} \mathrm{C}, 5 \mathrm{MPa}$ of $\mathrm{H}_{2}$ and $15 \mathrm{~min}$. However, no other temperatures or pressures were tested in that work. Deng et al. tested Ru/CNT (1 wt.\%) at 185 ${ }^{\circ} \mathrm{C}, 5 \mathrm{MPa}$ and $180 \mathrm{~min}$ achieved a yield to sorbitol of $87 \%$ [26]. At comparable experimental conditions of pressure and temperature $\left(180^{\circ} \mathrm{C}\right.$ and $\left.5 \mathrm{MPa}\right), \mathrm{Ru} / \mathrm{Al}-\mathrm{MCM}-48$ showed a slightly lower yield to sorbitol of $82 \%$ after $7 \mathrm{~min}$ of reaction time, but a specific reaction rate of 7.89 $\mathrm{mol}_{\text {Sorbitol }} \cdot \mathrm{mol}_{\mathrm{Ru}}{ }^{-1} \cdot \mathrm{min}^{-1}$, much larger than the $0.98 \mathrm{~mol}_{\text {Sorbitol }} \cdot \mathrm{mol}_{\mathrm{Ru}}{ }^{-1} \cdot \mathrm{min}^{-1}$ recorded for $\mathrm{Ru} / \mathrm{CNT}$. 
Comparing the catalytic activity of both materials, the results demonstrated that Ru/Al-MCM-48 outperformed the reaction rate obtained by $\mathrm{Ru} / \mathrm{CNT}$ around 8 times. Moreover, other authors reported catalytic systems combining homogeneous or heteropolyacids with supported Ru-based catalysts with this purpose. Negahdar et al. studied the conversion of cellobiose to sorbitol with a catalytic system consisting of silicotungstic acid (HPA) and a supported ruthenium catalyst (Ru/C, 5 wt.\%, Sigma Aldrich). At $160{ }^{\circ} \mathrm{C}, 5 \mathrm{MPa}$ and 70 min a yield to sorbitol of $68 \%$ was obtained. Ru/Al-MCM-48 presented in this work demonstrated approximately 3.7 times higher specific reaction rate under comparable reaction conditions $\left(160{ }^{\circ} \mathrm{C}, 5 \mathrm{MPa}\right.$ and $\left.30 \mathrm{~min}\right)$. In addition, the combination of $\mathrm{Ru} / \mathrm{C}+\mathrm{HPA}$ was not enough to improve the conversion rate of cellobiose compare to that obtained in the present work. Ru/Al-MCM-48 was able to achieve total conversion of cellobiose after $15 \mathrm{~min}$ of reaction time at $160{ }^{\circ} \mathrm{C}$ and $5 \mathrm{MPa}$, while $\mathrm{Ru} / \mathrm{C}+$ HPA reached $100 \%$ of cellobiose conversion after 70 min under similar reaction conditions. Zhang et al. examined $\mathrm{Ru} / \mathrm{C}$ catalyst $(3.6 \mathrm{wt} . \% \mathrm{Ru}$ ) for the direct conversion of cellobiose to sorbitol in 0.05 wt. $\% \mathrm{H}_{3} \mathrm{PO}_{4}$ solution [27]. In that work a yield to sorbitol around $87 \%$ was reached, showing a specific reaction rate of $1.58 \mathrm{~mol}_{\text {sorbitol }} \cdot \mathrm{mol}_{\mathrm{Ru}}{ }^{-1} \cdot \mathrm{min}^{-1}$ at $170{ }^{\circ} \mathrm{C}, 3 \mathrm{MPa}$ of $\mathrm{H}_{2}$ and $60 \mathrm{~min}$. The specific reaction rate related to the combination of $\mathrm{Ru} / \mathrm{C}+\mathrm{H}_{3} \mathrm{PO}_{4}$ was sligthly lower than that obtained by Ru/Al-MCM-48 at lower temperature $\left(160^{\circ} \mathrm{C}\right)$ in the present work.

$\mathrm{Ru} / \mathrm{Al}-\mathrm{MCM}-48$ was recovered after different experiments in order to study the recycling and reusability of the catalyst in the hydrolysis/hydrogenation of cellobiose at $180{ }^{\circ} \mathrm{C}, 5 \mathrm{MPa}$ and 7 min. After one cycle of reaction the conversion of cellobiose was around $92 \%$, while using the fresh catalyst (reduced) complete conversion for cellobiose was reached. In addition, the yield of hexitols present in the final product after one cycle of reaction was much lower ( $25 \%$ hexitols) than that achieved over the fresh catalyst (91\% hexitols). In addition, glucose was detected as 
intermediate ( $3 \%$ yield of glucose), but cellobitol was the main intermediate presenting a yield around $60 \%$ in the final product. According to all these experimental results, it is suggested that metal phase of the catalyst could be modified after one cycle of reaction. This fact was confirmed by XRD (Figure 8), where Ru crystallite size increased from 1.9 to $5.5 \mathrm{~nm}$, due to sintering, even after very short reaction time. The detected increase in ruthenium crystallites suggested a considerably decrease in the active surface of the metal [41], which is related to the worse catalytic behavior of Ru/Al-MCM-48 after one cycle of reaction. A comparable loss of activity has been previously reported in the literature, affecting mainly to reaction selectivity [25]. In that work, the collapse of the porous structure justified the lower accessibility to acidic sites and a subsequent higher selectivity to the hydrogenated intermediate (cellobitol). This is in line with our observations, where the noticeable increase in $\mathrm{Ru}$ particle size can be attributed to a loss of internal area, reducing the accessibility to acidic sites. This result suggests that further work, including the use of textural promoters, is needed to improve the stability of this catalyst.

\subsection{Kinetic modelling}

Scheme 1 shows the proposed reaction pathway for the hydrolytic hydrogenation of cellobiose into hexitols, assuming that cellobitol pathway. First, cellobiose is hydrogenated into cellobitol $\left(\mathrm{k}_{1}\right)$, which is subsequently hydrolyzed into sorbitol $\left(\mathrm{k}_{2}\right)$. The so obtained sorbitol can be isomerized into mannitol $\left(\mathrm{k}_{3}\right)$ and iditol $\left(\mathrm{k}_{4}\right)$ and both of them can be further converted into degradation products $\left(\mathrm{k}_{5}\right.$ and $\left.\mathrm{k}_{6}\right)$. Other by-products from dehydration reaction of sorbitol, such as isosorbide and 1,4 - sorbitan, are not included in the proposed model since they were only detected in very low concentrations. 
A homogeneous catalytic kinetic model was proposed, by considering carbon mass balance close to $100 \%$ (as observed in Table 2). Given the large excess of hydrogen and the low concentration of cellobiose fed in the initial solution, all reaction pathways were considered to be pseudo-first order. Some assumptions were taken into account in the development of the proposed model: a) catalyst deactivation is not taking place during the catalytic tests and b) reaction products are weakly adsorbed on the active surface of the catalyst. Negahdar et al. assumed similar statements for their kinetic models for hydrogenation reactions of cellobiose [24]. However, two main differences can be found between the model here proposed and the reported by Negahdar. First, conversion of sorbitol into mannitol or iditol is considered. This two isomerization products are detected to a higher extent than sorbitan or isosorbide. Second, the model includes the effect of reaction temperature by the orthogonalised Arrhenius equation.

Diffusional constrains were evaluated to ensure that all reactions were conducted in the kinetic regime. Firstly, as it was demonstrated in the preliminary experiments (not shown) and stated by other authors [24], a stirring rate of $1200 \mathrm{rpm}$ prevents reactions from external diffusional constrains. Then, the Weisz-Prater criterion was used for the evaluation of internal diffusional constrains. The Weisz-Prater number $\left(N_{W-P}\right)$ should meet the following equation (5):

$$
N_{W-P}=r \cdot \frac{R_{p}^{2}}{D_{\text {eff }} \cdot C_{S}} \leq 0.3
$$

Being $R_{p}$ the catalyst average particle size $(35 \mu \mathrm{m}), r$ the measured reaction rate and $C_{S}$ the surface concentration (equal to the concentration in the reaction medium as there were no external diffusion limitations) [42]. The initial cellobiose concentration and consumption rate were respectively set as $C_{S}$ and $r$. On the other hand, the effective diffusivity was calculated as follows in equation 6 : 


$$
D_{e f f}=D \cdot \frac{\varepsilon}{\tau}
$$

being $D$ the bulk diffusivity of cellobiose-water and hydrogen-water in each case. The tortuosity $(\tau)$ and porosity $(\varepsilon)$ values were not available, so they were set as 4 and 0.5 , respectively [43]. Bearing in mind all these points and the calculated data in Table 4, the most restrictive $N_{W-P}$ value (for the mixture hydrogen-water and the reaction at $180{ }^{\circ} \mathrm{C}$ ) was 0.19 , so internal diffusional constrains could be considered negligible.

According to the proposed reaction network presented in Scheme 1, the following differential equations (Eq. 7 - Eq. 11) are proposed for the different compounds as a function of time.

$$
\begin{aligned}
& \frac{d C_{\text {Cellobiose }}}{d t}=-k_{1} \cdot C_{\text {Cellobiose }} \\
& \frac{d C_{\text {Cellobitol }}}{d t}=k_{1} \cdot C_{\text {Cellobiose }}-k_{2} \cdot C_{\text {Cellobitol }} \\
& \frac{d C_{\text {Sorbitol }}}{d t}=2 \cdot k_{2} \cdot C_{\text {Cellobitol }}-k_{3} \cdot C_{\text {Sorbitol }}-k_{4} \cdot C_{\text {Sorbitol }} \\
& \frac{d C_{\text {Mannitol }}}{d t}=k_{3} \cdot C_{\text {Sorbitol }}-k_{5} \cdot C_{\text {Mannitol }} \\
& \frac{d C_{\text {Iditol }}}{d t}=k_{4} \cdot C_{\text {Sorbitol }}-k_{6} \cdot C_{\text {Iditol }}
\end{aligned}
$$

Moreover, reaction rate constants in the present work are given by the orthogonalised Arrhenius equation as follow in equation 12:

$$
\begin{aligned}
& k_{j}=\overline{A_{\jmath}} \cdot \exp \left(-\frac{E_{a j}}{R} \cdot\left(\frac{1}{\theta}\right)\right) \\
& \overline{A_{J}}=A_{j} \cdot \exp \left(-\frac{E_{a j}}{R} \cdot\left(\frac{1}{\bar{T}}\right)\right)=\bar{k}_{J} \\
& \frac{1}{\theta}=\frac{1}{T_{j}}-\frac{1}{\bar{T}}
\end{aligned}
$$


Therefore, in the presented model; 12 parameters were estimated: 6 kinetic constants at the average temperature $k_{j}\left(\mathrm{~T}=160{ }^{\circ} \mathrm{C}\right)$ and 6 activation energy values $E a_{j}$. MATLAB was used for the numerical integration of the differential equations and for the estimation of the parameters by using non-linear regression. The experimental data was compared to those calculated with the kinetic model and the Residual Sum of Squares (RSS) to reach the optimal kinetic parameters. RSS was calculated as follows in equation 15:

$$
R S S=\sum_{i=1}^{n}\left(C_{e x p, i}-C_{c a l c, i}\right)^{2}
$$

where $n$ was related to the considered data set. The estimation of the parameter was carried out by means of a built-in option, i.e., by using the last estimation result as a starting point for the next one [44].

A comparison of calculated and experimental data versus reaction time profiles of cellobiose conversion to hexitols is presented in Figure $9(\mathrm{~A}, \mathrm{~B}, \mathrm{C})$ at 140,160 and $180^{\circ} \mathrm{C}$, respectively. The results so obtained demonstrated that the model predicted fairly well the concentrations of the different components involved in the general reaction mechanism. The kinetic model fits better at higher reaction temperatures to the experimental data than at lower temperatures, where small deviations can be observed. Estimated reaction rate constants at the average temperature and the corresponding activation energy values are summarized in Table 5, as well as the standard deviation percentages and the results from Student's t-test $(\alpha=0.1)$ for each parameter. At the average temperature $(\bar{T})$, the reaction rate constant $\left(\mathrm{min}^{-1}\right)$ for the catalytic hydrogenation of cellobiose into cellobitol is higher than that obtained for the subsequently hydrolysis of cellobitol towards sorbitol. This fact indicates that hydrolysis of cellobitol to sorbitol is the ratedetermining step of the proposed reaction pathway. Negahdar et al. in their kinetic investigation of the hydrogenation of cellobiose over $\mathrm{Ru} / \mathrm{C}+\mathrm{HPA}$ also observed that hydrolysis steps showed 
lower reaction rates than those reached for the hydrogenation processes [24]. The rate constants related to further isomerization processes of sorbitol to mannitol $\left(\mathrm{k}_{3}\right)$ and iditol $\left(\mathrm{k}_{4}\right)$ and the subsequent degradation of both mannitol and iditol $\left(\mathrm{k}_{5}, \mathrm{k}_{6}\right)$, respectively, are smaller compared to $\mathrm{k}_{1}$ and $\mathrm{k}_{2}$. Regarding activation energy values, hydrogenation of cellobiose to cellobitol was determined to be around $\mathrm{Ea}_{1}=68 \mathrm{KJ} \cdot \mathrm{mol}^{-1}$. This activation energy value compares well with that reported by Tan et al. for the hydrogenation of cellobiose to cellobitol over Ru/CNT $\left(71 \mathrm{KJ} \cdot \mathrm{mol}^{-}\right.$ $\left.{ }^{1}\right)$ [45]. In addition, the activation energy of Ru/Al-MCM-48 was also lower than that reached by $\mathrm{Ru} / \mathrm{C}$ in the research work of Negahdar et al. $\left(76 \mathrm{KJ} \cdot \mathrm{mol}^{-1}\right)[24]$. Then, the activation energy value for the hydrolysis of cellobitol to sorbitol was $\mathrm{Ea}_{2}=136 \mathrm{KJ} \cdot \mathrm{mol}^{-1}$, which was higher than $\mathrm{Ea}_{1}$. This fact is pointing out that hydrolysis of cellobitol to sorbitol is more complicated than the previous hydrogenation of cellobiose to cellobitol. $\mathrm{Ea}_{2}$ achieved over Ru/Al-MCM-48 is in the same range of activation energies reported in the literature for the same reaction step (103 $\mathrm{KJ} \cdot \mathrm{mol}^{-1}$ ) [24]. Activation energy presented by Negahdar et al. was lower than that presented in this work for the hydrolysis of cellobiose to sorbitol since the used HPA combined with Ru/C enhancing hydrolysis processes. The corresponding activation energies for isomerization of sorbitol were $\mathrm{Ea}_{3}=101 \mathrm{KJ} \cdot \mathrm{mol}^{-1}$ and $\mathrm{Ea}_{4}=88 \mathrm{KJ} \cdot \mathrm{mol}^{-1}$, respectively. These values, lower than $\mathrm{Ea}_{2}$, agree with the increasing yield to sorbitol when increasing reaction temperature. The highest activation energy for sorbitol isomerization into mannitol indicates a higher temperature sensitivity of this step compared to isomerization of sorbitol to iditol. Furthermore, the same activation energy values were obtained in both cases for the final conversion of mannitol and iditol to other degradation products $\left(110 \mathrm{KJ} \cdot \mathrm{mol}^{-1}\right)$. The Student's t-test results lets the validation of the statistical significance of the different parameters estimated with the proposed model as it was previously reported by Lopez-González et al. [46]. Figure 9D shows the parity plot between 
estimated and experimental concentration of the different compounds involved in the proposed model. The so obtained results suggest that there were no correlation issues in the proposed kinetic model, whereas all the estimated parameters were statistically significant.

\section{Conclusions}

The experimental results presented above support the following conclusions:

i) Maximum yield to hexitol around $91 \%$ was obtained at $180{ }^{\circ} \mathrm{C}, 7$ min and $5 \mathrm{MPa}$ of $\mathrm{H}_{2}$ over Ru/Al-MCM-48.

ii) $\mathrm{Ru} / \mathrm{Al}-\mathrm{MCM}-48$ demonstrated higher activity in the one-pot catalytic conversion of cellobiose than other catalytic systems reported in the literature such as Ru/C + HPA, $\mathrm{Ru} / \mathrm{CNT}, \mathrm{Ru} / \mathrm{SBA}-15$ and $\mathrm{Ru} / \mathrm{C}+\mathrm{H}_{3} \mathrm{PO}_{4}$.

iii) The kinetic model developed predicted well the concentration of the different reactants and products involved in the reaction, yielding kinetic parameters with statistical significance.

iv) Loss of activity, with sintering of ruthenium, was detected after one cycle of reaction, conducting to a worse catalytic behavior than that observed for the fresh catalyst.

\section{Acknowledgements}

The authors gratefully acknowledge the Spanish Ministry, MINECO, and FEDER founds for the financial support of this project CTQ2015-64892-R (MINECO/FEDER). A. Romero thanks 
to the program of predoctoral scholarships from Junta de Castilla y León Government for his grant (E-47-2015-0062773).

\section{References}

[1] A. Fukuoka, P.L. Dhepe, Angew. Chem. Int. Ed., 118 (2006) 5285-5287.

[2] Y. Roman-Leshkov, C.J. Barrett, Z.Y. Liu, J.A. Dumesic, Nature, 447 (2007) 982-985.

[3] R.D. Cortright, R.R. Davda, J.A. Dumesic, Nature, 418 (2002) 964-967.

[4] J. Xi, Y. Zhang, Q. Xia, X. Liu, J. Ren, G. Lu, Y. Wang, Appl. Catal. A Gen., 459 (2013) 5258.

[5] J.C. Serrano-Ruiz, J.A. Dumesic, Energ. Environ. Sci., 4 (2011) 83-99.

[6] T. Rogalinski, T. Ingram, G. Brunner, J. Supercrit. Fluid., 47 (2008) 54-63.

[7] G. Liang, C. Wu, L. He, J. Ming, H. Cheng, L. Zhuo, F. Zhao, Green Chem., 13 (2011) 839842.

[8] A. Romero, D.A. Cantero, A. Nieto-Marquez, C. Martinez, E. Alonso, M.J. Cocero, Green Chem., 18 (2016) 4051-4062.

[9] A. Romero, E. Alonso, Á. Sastre, A. Nieto-Márquez, Micropor. Mesopor. Mat., 224 (2016) $1-8$.

[10] R. Palkovits, K. Tajvidi, A.M. Ruppert, J. Procelewska, Chem. Commun., 47 (2011) 576578.

[11] J. Chen, S. Wang, J. Huang, L. Chen, L. Ma, X. Huang, ChemSusChem, 6 (2013) 15451555.

[12] H. Kobayashi, H. Ohta, A. Fukuoka, Catal. Sci. Technol., 2 (2012) 869-883.

[13] M. Schlaf, Z.C. Zhang, Reaction Pathways and Mechanisms in Thermocatalytic Biomass Conversion I, Springer, 2016.

[14] L.P. Walker, D.B. Wilson, Bioresour. Technol., 36 (1991) 3-14.

[15] S. Kassaye, K.K. Pant, S., Fuel Process. Technol., 148 (2016) 289-294.

[16] S.E. Jacobsen, C.E. Wyman, Cellulose and Hemicellulose Hydrolysis Models for Application to Current and Novel Pretreatment Processes, Humana Press, Totowa, NJ, 2000, pp. 81-96.

[17] A. Onda, T. Ochi, K. Yanagisawa, Green Chem., 10 (2008) 1033-1037.

[18] D.A. Cantero, M. Dolores Bermejo, M. José Cocero, Bioresour. Technol., 135 (2013) 697703.

[19] A.A. Dabbawala, D.K. Mishra, J.-S. Hwang, Catal. Today, 265 (2016) 163-173.

[20] P.A. Lazaridis, S. Karakoulia, A. Delimitis, S.M. Coman, V.I. Parvulescu, K.S. Triantafyllidis, Catal. Today, 257, Part 2 (2015) 281-290.

[21] L.-N. Ding, A.-Q. Wang, M.-Y. Zheng, T. Zhang, ChemSusChem, 3 (2010) 818-821.

[22] H. Kobayashi, Y. Ito, T. Komanoya, Y. Hosaka, P.L. Dhepe, K. Kasai, K. Hara, A. Fukuoka, Green Chem., 13 (2011) 326-333.

[23] N. Yan, C. Zhao, C. Luo, P.J. Dyson, H. Liu, Y. Kou, J. Am. Chem. Soc., 128 (2006) 87148715.

[24] L. Negahdar, J.U. Oltmanns, S. Palkovits, R. Palkovits, Appl. Catal. B Environ., 147 (2014) 677-683. 
[25] Y. Niu, H. Wang, X. Zhu, Z. Song, X. Xie, X. Liu, J. Han, Q. Ge, Micropor. Mesopor. Mater., 198 (2014) 215-222.

[26] W. Deng, M. Liu, X. Tan, Q. Zhang, Y. Wang, J. Catal., 271 (2010) 22-32.

[27] J. Zhang, S. Wu, B. Li, H. Zhang, Catal. Commun., 29 (2012) 180-184.

[28] J. Li, H.S.M.P. Soares, J.A. Moulijn, M. Makkee, Catal. Sci. Technol., 3 (2013) 1565-1572.

[29] A. Romero, A. Nieto-Márquez, E. Alonso, Appl. Catal. A Gen., 529 (2017) 49-59.

[30] B.T. Kusema, L. Faba, N. Kumar, P. Mäki-Arvela, E. Díaz, S. Ordóñez, T. Salmi, D.Y. Murzin, Catal. Today, 196 (2012) 26-33.

[31] C. Amorim, M.A. Keane, J. Colloid Interf. Sci., 322 (2008) 196-208.

[32] H. Kosslick, G. Lischke, H. Landmesser, B. Parlitz, W. Storek, R. Fricke, J. Catal., 176 (1998) 102-114.

[33] C. Danumah, S. Vaudreuil, L. Bonneviot, M. Bousmina, S. Giasson, S. Kaliaguine, Micropor. Mesopor. Mat., 44-45 (2001) 241-247.

[34] S.K. Seshadri, Y.S. Lin, Sep. Purif. Technol., 76 (2011) 261-267.

[35] S. Brunauer, L.S. Deming, W.E. Deming, E. Teller, J. Am. Chem. Soc., 62 (1940) 17231732.

[36] K. Schumacher, P.I. Ravikovitch, A. Du Chesne, A.V. Neimark, K.K. Unger, Langmuir, 16 (2000) 4648-4654.

[37] J. Meng, Y. Cao, G. Zheng, J. Li, H. Wu, X. Guan, X. Zheng, Mat. Res. Bull., 60 (2014) 2027.

[38] D. Eliche-Quesada, J. Mérida-Robles, E. Rodríguez-Castellón, A. Jiménez-López, Appl. Catal. B Environ., 65 (2006) 118-126.

[39] P.K. Vanama, A. Kumar, S.R. Ginjupalli, V.R.C. Komandur, Catal. Today, 250 (2015) 226238.

[40] J. Li, A. Spina, J.A. Moulijn, M. Makkee, Catal. Sci. Technol., 3 (2013) 1540-1546. [41] H.G. Manyar, D. Weber, H. Daly, J.M. Thompson, D.W. Rooney, L.F. Gladden, E. Hugh Stitt, J. Jose Delgado, S. Bernal, C. Hardacre, J. Catal., 265 (2009) 80-88.

[42] M.A. Vannice, Kinetics of Catalytic Reactions, Springer US2005.

[43] M. E. Davis, R.J. Davis, Fundamentals of Chemical Reaction Engineering, McGrawHill2002.

[44] J.A. Díaz, E. Skrzyńska, J.-S. Girardon, J. Ftouni, M. Capron, F. Dumeignil, P. Fongarland, Eur. J. Lipid Sci. Technol., 118 (2016) 72-79.

[45] X. Tan, X. Zhuang, W. Deng, Q. Zhang, Y. Wang, Z. Yuan, CIESC J., 10 (2010) 015.

[46] D. López-González, M. Fernandez-Lopez, J.L. Valverde, L. Sanchez-Silva, Energy, 73 (2014) 33-43. 
Table 1. Textural properties, ruthenium loading, ruthenium particle size and acidity of Al-MCM-48 and Ru/AlMCM-48.

\begin{tabular}{|c|c|c|c|c|c|c|}
\hline Catalyst & $\begin{array}{l}\mathrm{Ru} \\
(\%)\end{array}$ & $\begin{array}{c}\mathrm{S}_{\text {BET }} \\
\left(\mathrm{m}^{2} \cdot \mathrm{g}^{-1}\right)\end{array}$ & $\begin{array}{c}V_{\text {pore }} \\
\left(\mathrm{cm}^{3} \cdot \mathrm{g}^{-1}\right)\end{array}$ & $\begin{array}{l}\emptyset_{\text {pore }} \\
(\mathbf{n m})\end{array}$ & $\begin{array}{l}\text { Ru } \\
(\mathbf{n m})\end{array}$ & $\begin{array}{c}\text { Acidity } \\
\left(\mathrm{mmol}_{\mathrm{NH} 3} \cdot \mathrm{g}^{-1}\right)\end{array}$ \\
\hline Al-MCM-48 & - & 1352 & 0.81 & 2.5 & - & 0.84 \\
\hline Ru/Al-MCM-48 & 3.5 & 1028 & 0.57 & 2.7 & $2.0^{\mathrm{a}} / 1.9^{\mathrm{b}}$ & 1.22 \\
\hline
\end{tabular}

${ }^{a} \mathrm{Ru}$ surface-area weighted diameter from TEM images. ${ }^{\mathrm{b}} \mathrm{Ru}$ crystallite size from XRD analysis. 
Table 2. Maximum yield to hexitols, composition of the final product and mass balances at different temperatures.

\begin{tabular}{|c|c|c|c|c|c|c|c|c|c|}
\hline \multirow[b]{2}{*}{$\begin{array}{c}\mathrm{T} \\
\left({ }^{\circ} \mathrm{C}\right)\end{array}$} & \multicolumn{9}{|c|}{ Yield (\% C) } \\
\hline & $\begin{array}{c}\mathbf{t} \\
(\mathrm{min})\end{array}$ & $\begin{array}{c}\mathbf{X}_{\mathrm{C}} \\
(\% \mathrm{C})\end{array}$ & Cellobitol & Sorbitol & Mannitol & Iditol & Hexitols & $\begin{array}{c}\text { 1,4- } \\
\text { Sorbitan }\end{array}$ & $\begin{array}{c}\text { MB } \\
(\% \mathrm{C})\end{array}$ \\
\hline 140 & 240 & 100 & 9.5 & 64.7 & 13.6 & 11.1 & 89.4 & 0 & 98.9 \\
\hline 160 & 30 & 100 & 10.7 & 76.3 & 7.7 & 3.5 & 87.5 & 0.1 & 98.3 \\
\hline 180 & 7 & 100 & 7.9 & 81.8 & 7.7 & 1.9 & 91.4 & 0.7 & 100 \\
\hline
\end{tabular}


Table 3. Conversion of cellobiose into sorbitol and specific reaction rate.

\begin{tabular}{|c|c|c|c|c|c|c|}
\hline Catalyst & $\begin{array}{l}\mathbf{R u} \\
(\%)\end{array}$ & $\begin{array}{c}\mathrm{T} \\
\left({ }^{\circ} \mathrm{C}\right)\end{array}$ & $\begin{array}{c}\mathbf{t} \\
(\mathrm{min})\end{array}$ & $\begin{array}{c}\mathbf{Y}_{\text {Sorbitol }} \\
(\%)\end{array}$ & $\begin{array}{c}\text { Activity } \\
\left(\mathrm{mol}_{\text {Sorbitol }} \cdot \mathbf{m o l}_{\mathrm{Ru}}{ }^{-1} \cdot \mathrm{min}^{-1}\right)\end{array}$ & Reference \\
\hline \multirow{3}{*}{ Ru/Al-MCM-48 } & & 140 & 15 & 17 & 0.75 & \multirow{3}{*}{ This work } \\
\hline & 3.5 & 160 & 30 & 76 & 1.72 & \\
\hline & & 180 & 7 & 82 & 7.89 & \\
\hline $\mathrm{Ru} / \mathrm{C}+\mathrm{HPA}$ & 5 & 160 & 70 & 68 & $0.46^{\mathrm{a}}$ & [24] \\
\hline $\mathrm{Ru} / \mathrm{C}+\mathrm{H}_{3} \mathrm{PO}_{4}$ & 3.6 & 170 & 60 & 87 & $1.58^{\mathrm{a}}$ & {$[27]$} \\
\hline $\mathrm{Ru} / \mathrm{SBA}-15$ & 1.7 & 140 & 15 & 4 & $0.46^{\mathrm{a}}$ & {$[25]$} \\
\hline $\mathrm{Ru} / \mathrm{Zr}-\mathrm{SBA}-15$ & 1.8 & 140 & 15 & 14.6 & $1.59^{\mathrm{a}}$ & {$[25]$} \\
\hline $\mathrm{Ru} / \mathrm{CNT}$ & 1 & 185 & 180 & 87 & $0.98^{\mathrm{a}}$ & {$[26]$} \\
\hline
\end{tabular}

${ }^{\mathrm{a}}$ Activity (molSorbitol $\cdot \mathrm{molRu}^{-1} \cdot \mathrm{min}^{-1}$ ) calculated from the catalytic data reported in each work. 
Table 4. Derived calculations from the evaluation of internal diffusional constrains by the Weisz-Prater criterion.

\begin{tabular}{cccc}
\hline Parameter & $\mathbf{T}=\mathbf{1 4 0}^{\mathbf{}} \mathbf{C}$ & $\mathbf{T}=\mathbf{1 6 0}^{\mathbf{}} \mathbf{C}$ & $\mathbf{T}=\mathbf{1 8 0}^{\mathbf{}} \mathbf{C}$ \\
\hline$N w-p \mathrm{H}_{2}$-water & $7.2 \cdot 10^{-2}$ & $1.4 \cdot 10^{-1}$ & $1.9 \cdot 10^{-1}$ \\
$N w$ - $p$ cellobiose-water & $9.4 \cdot 10^{-3}$ & $2.4 \cdot 10^{-2}$ & $6.7 \cdot 10^{-2}$ \\
$D \mathrm{H}_{2}$-water $\left(\mathrm{m}^{2} \cdot \mathrm{s}^{-1}\right)$ & $1.7 \cdot 10^{-9}$ & $2.1 \cdot 10^{-9}$ & $2.5 \cdot 10^{-9}$ \\
$D$ cellobiose-water $\left(\mathrm{m}^{2} \cdot \mathrm{s}^{-1}\right)$ & $3.6 \cdot 10^{-9}$ & $4.2 \cdot 10^{-9}$ & $4.8 \cdot 10^{-9}$ \\
$D_{\text {eff }} \mathrm{H}_{2}$-water $\left(\mathrm{m}^{2} \cdot \mathrm{s}^{-1}\right)$ & $2.2 \cdot 10^{-10}$ & $2.6 \cdot 10^{-10}$ & $3.1 \cdot 10^{-10}$ \\
$D_{\text {eff }}$ cellobiose-water $\left(\mathrm{m}^{2} \cdot \mathrm{s}^{-1}\right)$ & $4.4 \cdot 10^{-10}$ & $5.2 \cdot 10^{-10}$ & $5.9 \cdot 10^{-10}$ \\
Henry constant $\left(\mathrm{mol} \cdot \mathrm{l}^{-1} \cdot \mathrm{bar}^{-1}\right)$ & $4.9 \cdot 10^{-4}$ & $4.6 \cdot 10^{-4}$ & $4.4 \cdot 10^{-4}$ \\
\hline
\end{tabular}


Table 5. Estimated kinetic parameter, standard deviation percentages and t-test

\begin{tabular}{cccc}
\hline Parameter $^{\mathrm{a}}$ & Estimate & $|\boldsymbol{\sigma}| \mathbf{( \% )}$ & t-test $^{\mathbf{b}} /$ Meaningful? \\
\hline $\mathrm{k}_{1}(\bar{T})$ & $4.80 \cdot 10^{-1}$ & 19.31 & $5.18 / \mathrm{YES}$ \\
$\mathrm{Ea}_{1}$ & 68.05 & 17.85 & $5.60 / \mathrm{YES}$ \\
$\mathrm{k}_{2}(\bar{T})$ & $1.20 \cdot 10^{-1}$ & 2.14 & $46.69 / \mathrm{YES}$ \\
$\mathrm{Ea}_{2}$ & 136.37 & 0.14 & $722.29 / \mathrm{YES}$ \\
$\mathrm{k}_{3}(\bar{T})$ & $4.30 \cdot 10^{-3}$ & 1.04 & $95.83 / \mathrm{YES}$ \\
$\mathrm{Ea}_{3}$ & 100.50 & 5.46 & $18.33 / \mathrm{YES}$ \\
$\mathrm{k}_{4}(\bar{T})$ & $2.40 \cdot 10^{-3}$ & 1.11 & $90.48 / \mathrm{YES}$ \\
$\mathrm{Ea}_{4}$ & 88.25 & 2.39 & $41.87 / \mathrm{YES}$ \\
$\mathrm{k}_{5}(\bar{T})$ & $9.50 \cdot 10^{-3}$ & 2.48 & $40.30 / \mathrm{YES}$ \\
$\mathrm{Ea}_{5}$ & 110.03 & 10.36 & $9.65 / \mathrm{YES}$ \\
$\mathrm{k}_{6}(\bar{T})$ & $9.50 \cdot 10^{-3}$ & 2.48 & $40.30 / \mathrm{YES}$ \\
$\mathrm{Ea}_{6}$ & 110.03 & 10.36 & $9.65 / \mathrm{YES}$
\end{tabular}

${ }^{\mathrm{a}} \bar{T}=160{ }^{\circ} \mathrm{C}, \mathrm{k}_{\mathrm{j}}(\bar{T}) /\left(\mathrm{min}^{-1}\right)$ and $\mathrm{Ea}_{\mathrm{j}}\left(\mathrm{KJ} \cdot \mathrm{mol}^{-1}\right)$.

${ }^{\mathrm{b}} \mathrm{t}(\mathrm{n}-\mathrm{p}, 1-\alpha / 2)=\mathrm{t}(170,0.95)=1.98$. 


\section{Figure and Scheme captions}

Figure 1. SAXS pattern of Al-MCM-48.

Figure 2. $\mathrm{N}_{2}$ adsorption - desorption isotherms and pore size distributions of Al-MCM-48 and Ru/Al-MCM-48.

Figure 3. (A) $\mathrm{H}_{2}$-TPR of Ru/Al-MCM- 48 and (B) XRD patterns of Al-MCM-48, Ru/Al-MCM48 and activated Ru/Al-MCM-48.

Figure 4. (A) (B) TEM images and (C) ruthenium particle size distribution of Ru/Al-MCM-48 (excluding agglomerates).

Figure 5. Kinetics of hydrogenolysis of cellobiose at (A) $140{ }^{\circ} \mathrm{C}$, (B) $160^{\circ} \mathrm{C},(\mathbf{C}) 180{ }^{\circ} \mathrm{C}$ and 5 MPa of $\mathrm{H}_{2} \cdot \square$ Cellobiose, $\bullet$ Cellobitol, $\Delta$ Glucose, $\boldsymbol{\Delta}$ Sorbitol, $\boldsymbol{\nabla}$ Mannitol, $\bullet$ Iditol, $\square$ 1,4 Sorbitan and $\circ$ Isosorbide.

Figure 6.Effect of temperature (A) and pressure (B) in the conversion of cellobiose and yield to hexitols over Ru/Al-MCM-48.(A) $\square \mathrm{T}=140{ }^{\circ} \mathrm{C}, \square \mathrm{T}=160^{\circ} \mathrm{C}, \square \mathrm{T}=180^{\circ} \mathrm{C}, 5 \mathrm{MPa}$ of $\mathrm{H}_{2}$ and 5 min. (B) $\square \mathrm{P}=3 \mathrm{MPa}$ of $\mathrm{H}_{2}, \square \mathrm{P}=4 \mathrm{MPa}$ of $\mathrm{H}_{2}, \square \mathrm{P}=5 \mathrm{MPa}$ of $\mathrm{H}_{2}, 180$ ${ }^{\circ} \mathrm{C}$ and 7 min.

Figure 7. Concentration profiles during the conversion of cellobiose at (A) $3 \mathrm{MPa}$ of $\mathrm{H}_{2}$, (B) 4 MPa of $\mathrm{H}_{2}$, (C) $5 \mathrm{MPa}$ of $\mathrm{H}_{2}$ and $180^{\circ} \mathrm{C}$. Cellobiose, $\bullet$ Cellobitol, $\triangle$ Glucose, $\Delta$ Sorbitol, Mannitol, $\bullet$ Iditol, $\square$ 1,4 - Sorbitan and ○ Isosorbide.

Figure 8. Recycling of the catalyst at $180^{\circ} \mathrm{C}, 5 \mathrm{MPa}$ of $\mathrm{H}_{2}$ and $7 \mathrm{~min}$ ( 1 cycle). $\mathrm{XRD}$ of fresh Ru/Al-MCM-48 and 1 cycle Ru/Al-MCM-48.

Figure 9. Experimental and calculated concentration vs. time profiles of cellobiose hydrogenolysis into hexitols. (A) $\mathrm{T}=140{ }^{\circ} \mathrm{C},(\mathbf{B}) \mathrm{T}=160^{\circ} \mathrm{C}$, (C) $180{ }^{\circ} \mathrm{C}$ and $5 \mathrm{MPa}$ of $\mathrm{H}_{2}$ Cellobiose, $\bullet$ Cellobitol, $\boldsymbol{\Delta}$ Sorbitol, $\boldsymbol{\nabla}$ Mannitol, $\bullet$ Iditol and model. (D) Parity plot between experimental and estimated considerations. 
Scheme 1. Proposed reaction network for the catalytic conversion of cellobiose towards hexitols over Ru/Al-MCM-48. 


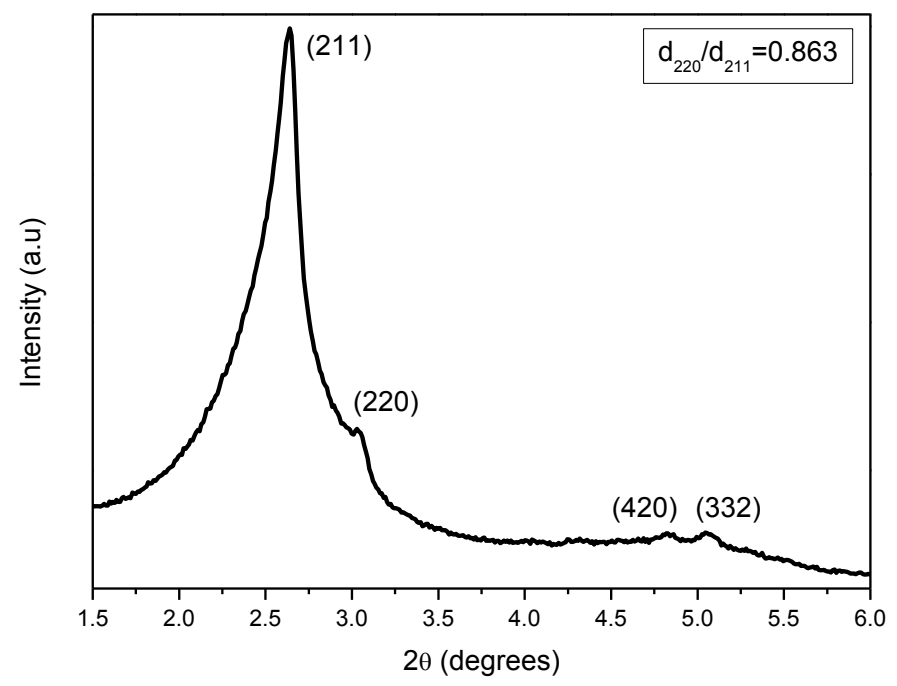

Figure 1. SAXS pattern of Al-MCM-48. 


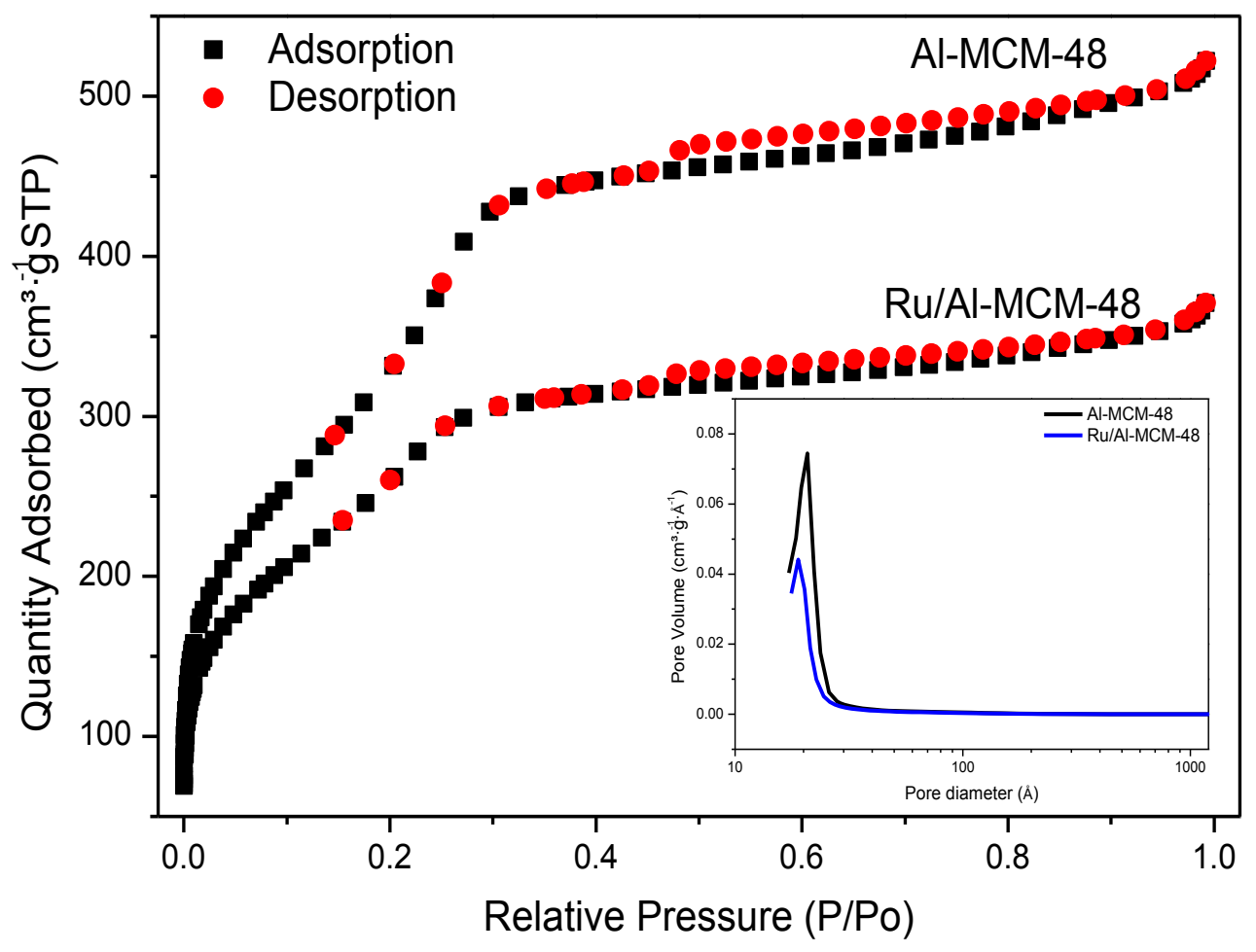

Figure 2. $\mathrm{N}_{2}$ adsorption - desorption isotherms and pore size distributions of Al-MCM-48 and Ru/Al-MCM-48. 

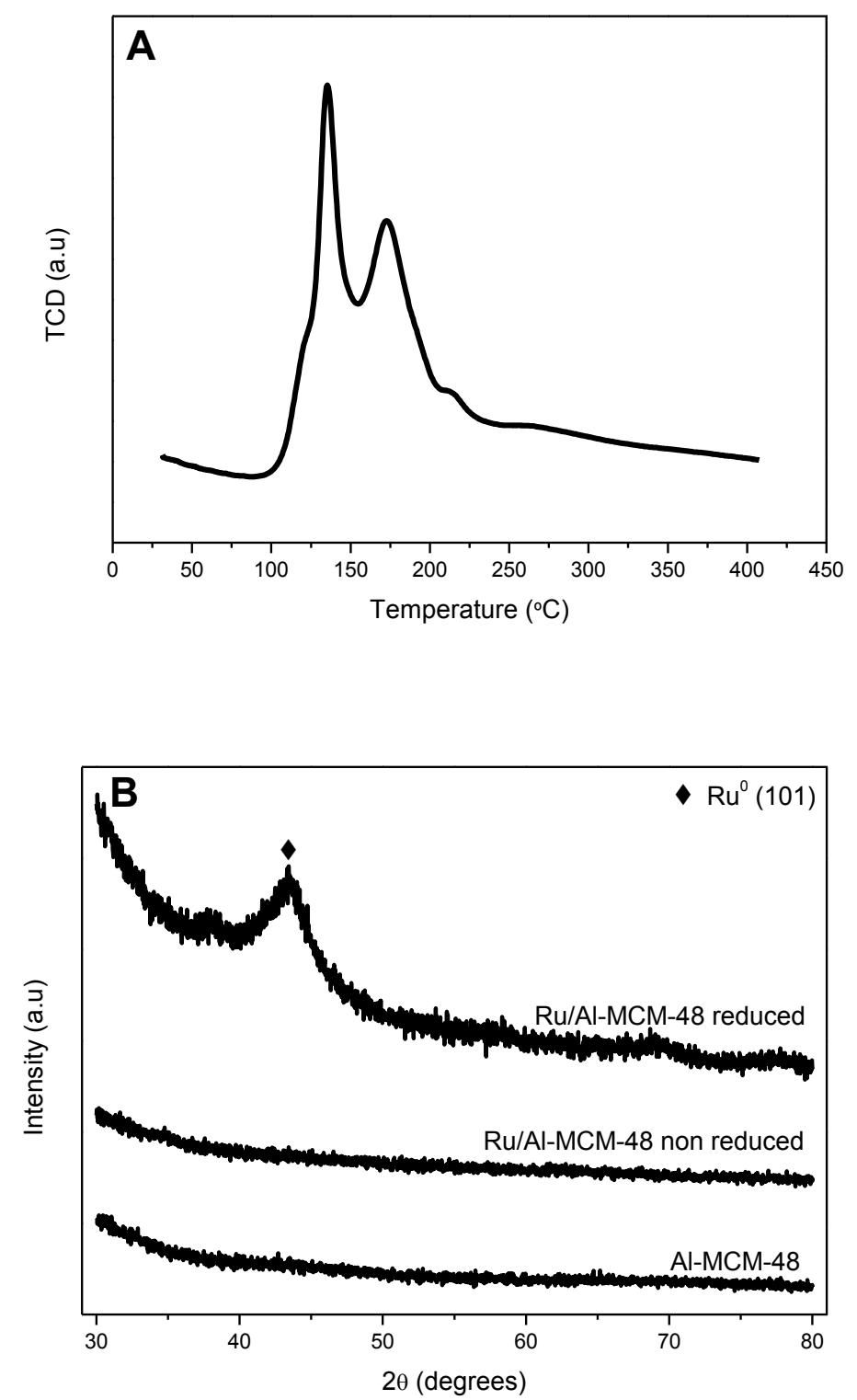

Figure 3. (A) $\mathrm{H}_{2}-\mathrm{TPR}$ of $\mathrm{Ru} / \mathrm{Al}-\mathrm{MCM}-48$ and (B) XRD patterns of Al-MCM-48, Ru/AlMCM-48 and activated Ru/Al-MCM-48. 

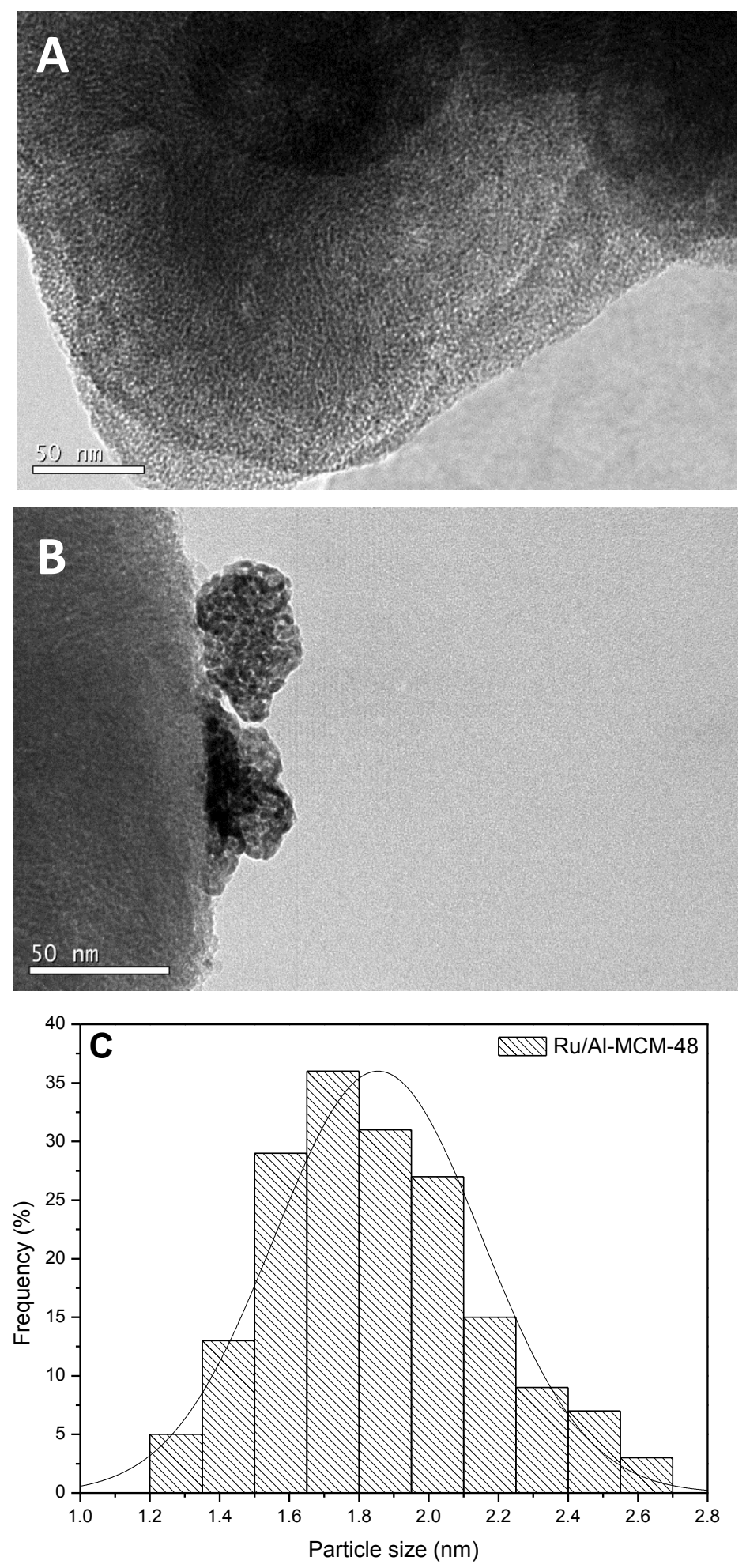

Figure 4. (A) (B) TEM images and (C) ruthenium particle size distribution of Ru/Al-MCM48 (excluding agglomerates). 

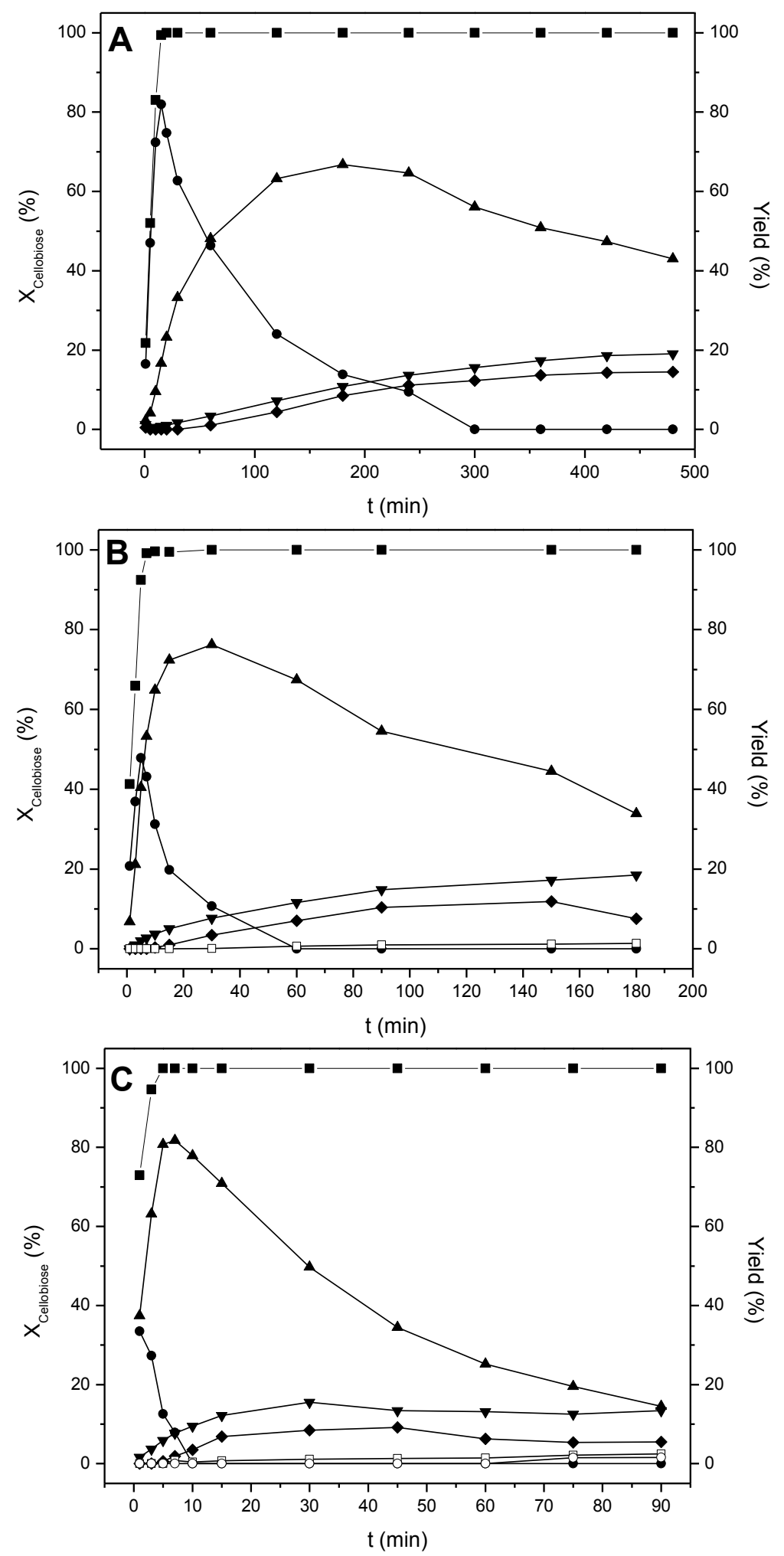

Figure 5. Concentration profiles during the conversion of cellobiose at (A) $140{ }^{\circ} \mathrm{C}$, (B) $160{ }^{\circ} \mathrm{C}$, (C) $180^{\circ} \mathrm{C}$ and $5 \mathrm{MPa}$ of $\mathrm{H}_{2} \cdot \mathbf{C}$ Cellobiose, $\bullet$ Cellobitol, $\triangle$ Glucose, $\Delta$ Sorbitol, $\nabla$ Mannitol, Iditol, $\square$ 1,4 - Sorbitan and $\circ$ Isosorbide. 

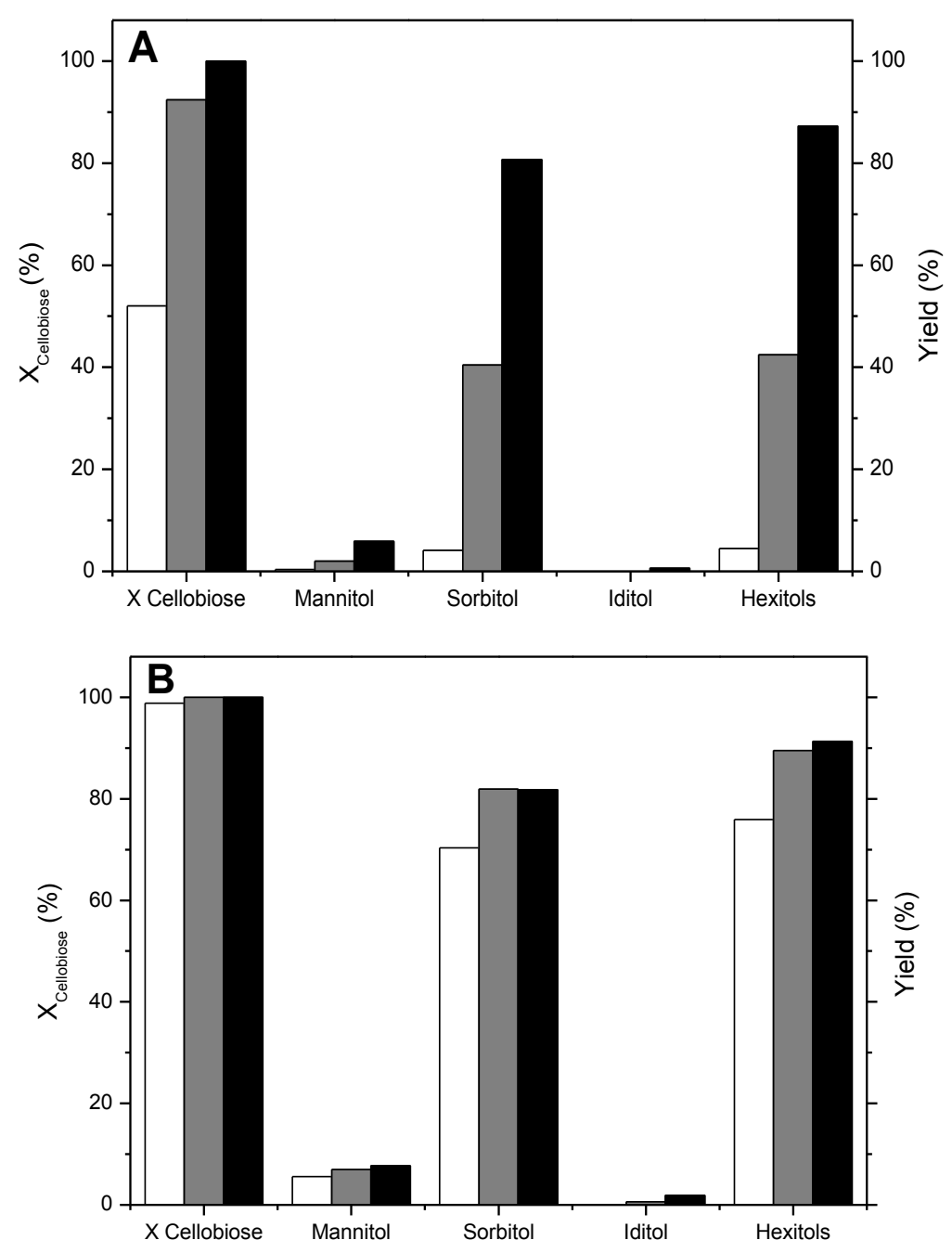

Figure 6. Effect of temperature (A) and pressure (B) in the conversion of cellobiose and yield to hexitols over Ru/Al-MCM-48. (A) $\square \mathrm{T}=140^{\circ} \mathrm{C}, \square \mathrm{T}=160^{\circ} \mathrm{C}, \square \mathrm{T}=180^{\circ} \mathrm{C}, 5$ of MPa $\mathrm{H}_{2}$ and 5 min. (B) $\square \mathrm{P}=3 \mathrm{MPa}$ of $\mathrm{H}_{2}, \square \mathrm{P}=4 \mathrm{MPa}$ of $\mathrm{H}_{2}, \square \mathrm{P}=5 \mathrm{MPa}^{2} \mathrm{H}_{2}$, $180^{\circ} \mathrm{C}$ and $7 \mathrm{~min}$. 

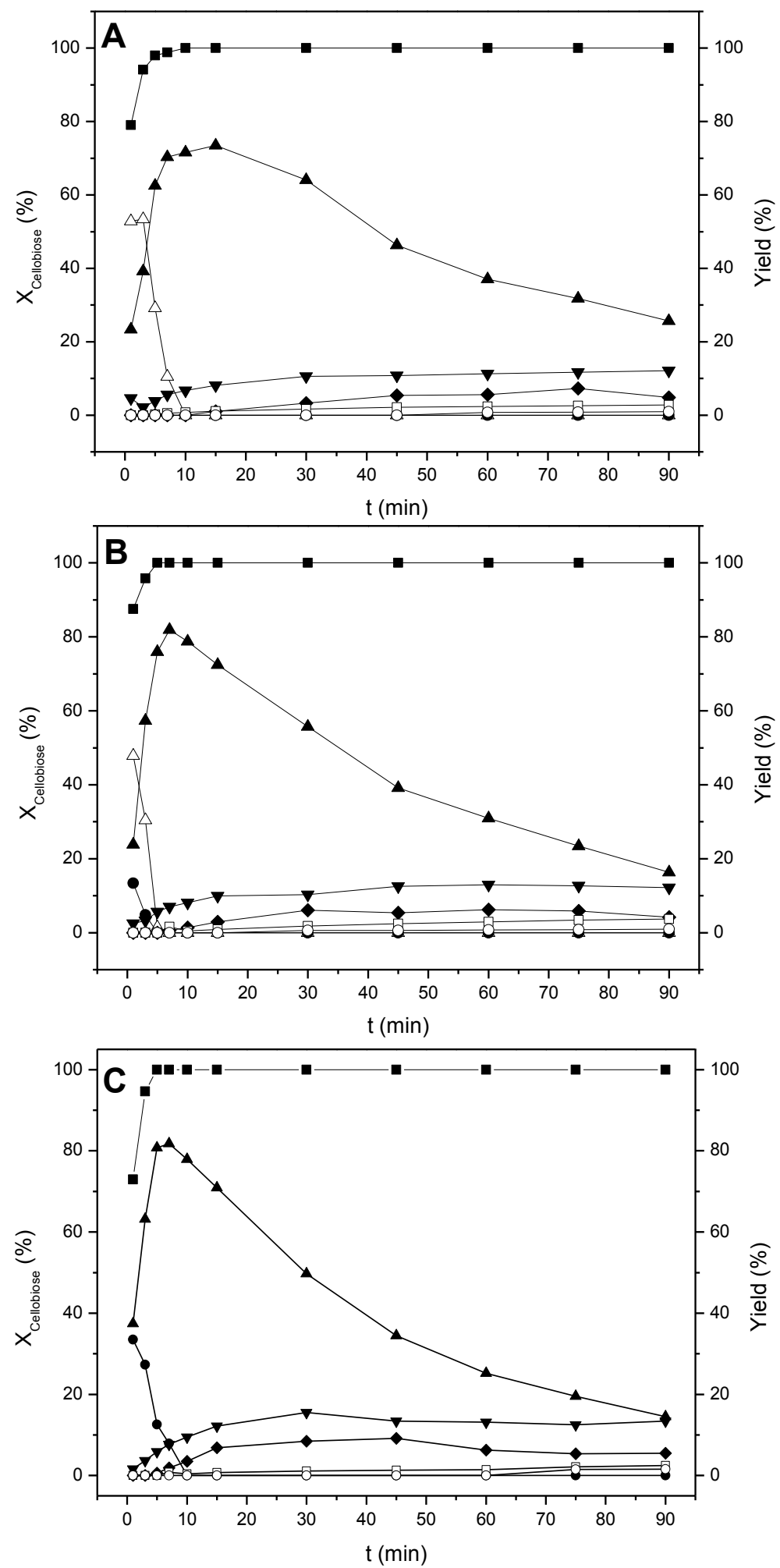

Figure 7. Kinetics of hydrogenolysis of cellobiose at (A) $3 \mathrm{MPa}$ of $\mathrm{H}_{2}$, (B) $4 \mathrm{MPa}$ of $\mathrm{H}_{2}$, (C) 5 MPa of $\mathrm{H}_{2}$ and $180{ }^{\circ} \mathrm{C}$. Cellobiose, $\bullet$ Cellobitol, $\triangle$ Glucose, $\Delta$ Sorbitol, $\boldsymbol{\nabla}$ Mannitol, $\bullet$ Iditol, $\square$ 1,4 - Sorbitan and $\circ$ Isosorbide. 


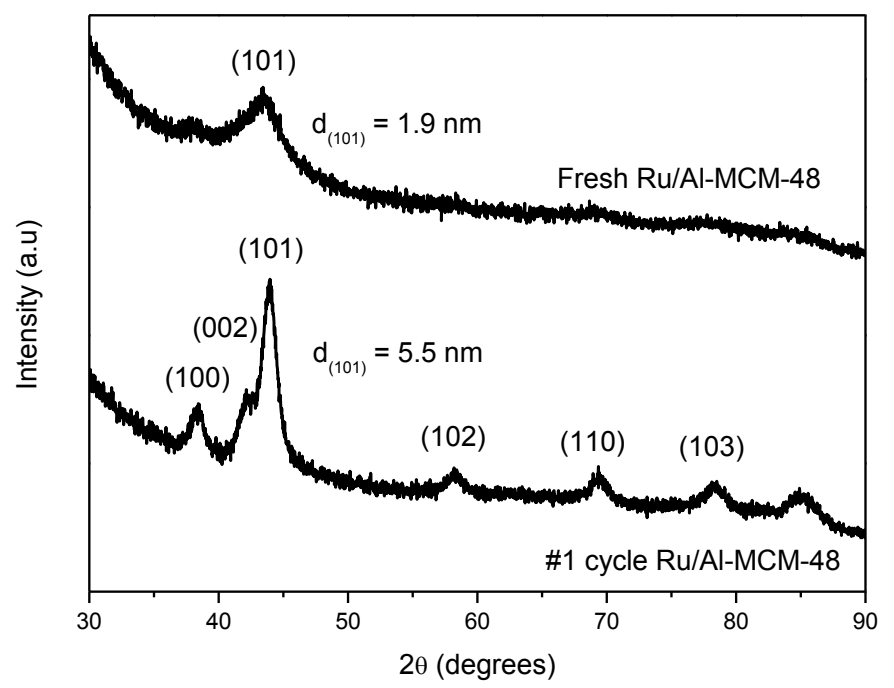

Figure 8. Recycling of the catalyst at $180{ }^{\circ} \mathrm{C}, 5 \mathrm{MPa}$ of $\mathrm{H}_{2}$ and $7 \mathrm{~min}$ ( 1 cycle). XRD of fresh Ru/Al-MCM-48 and 1 cycle Ru/Al-MCM-48. 

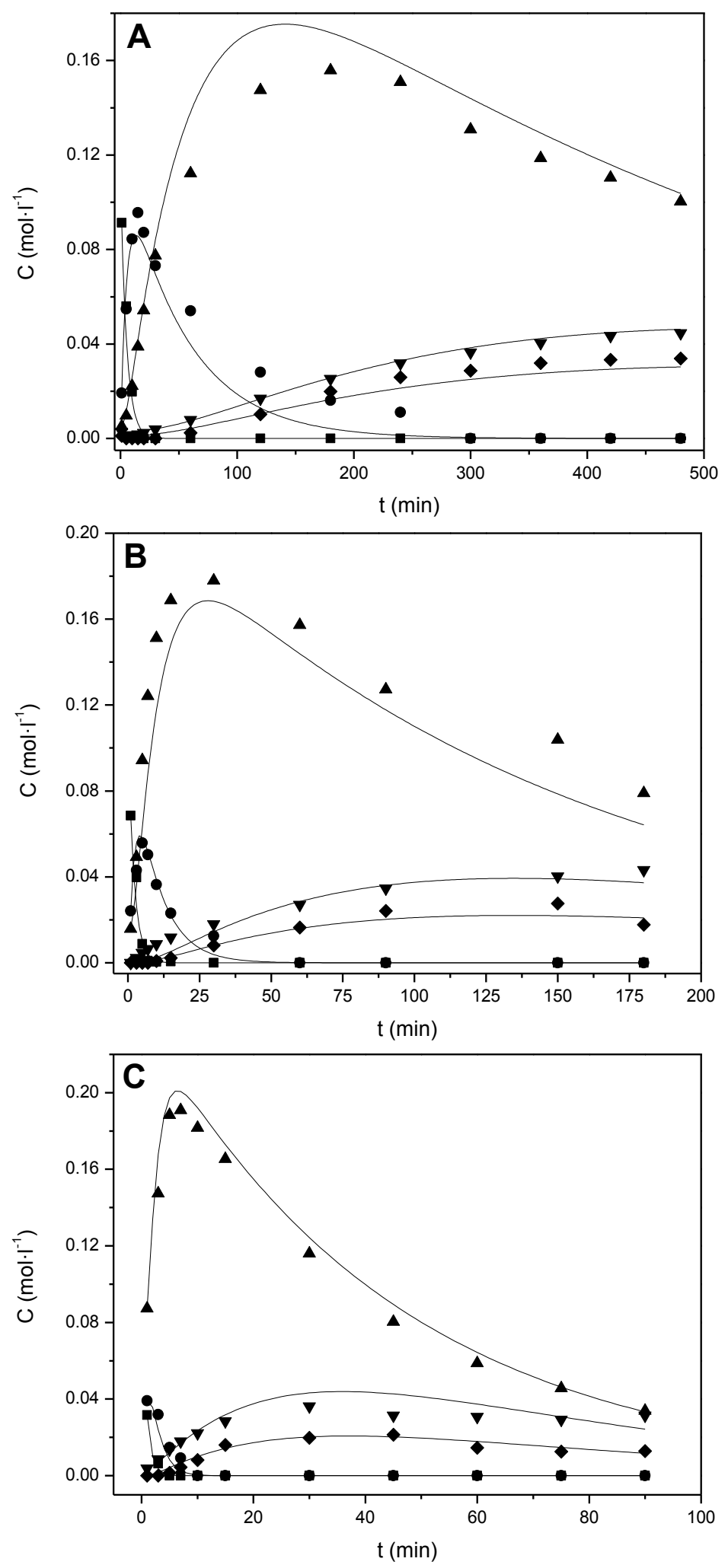


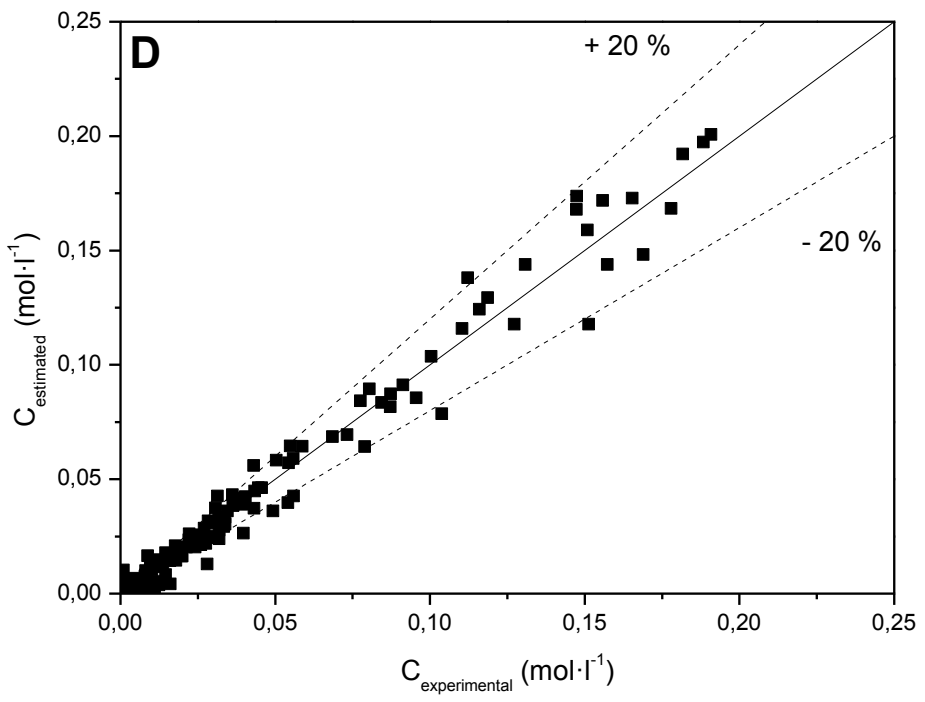

Figure 9. Experimental and calculated concentration vs. time profiles of cellobiose hydrogenolysis into hexitols. (A) $\mathrm{T}=140{ }^{\circ} \mathrm{C},(\mathbf{B}) \mathrm{T}=160{ }^{\circ} \mathrm{C}$, (C) $180{ }^{\circ} \mathrm{C}$ and $5 \mathrm{MPa}$ of $\mathrm{H}_{2}$. Cellobiose, $\bullet$ Cellobitol, $\boldsymbol{\Delta}$ Sorbitol, $\mathbf{\nabla}$ Mannitol, $\bullet$ Iditol and model. (D) Parity plot between experimental and estimated considerations. 


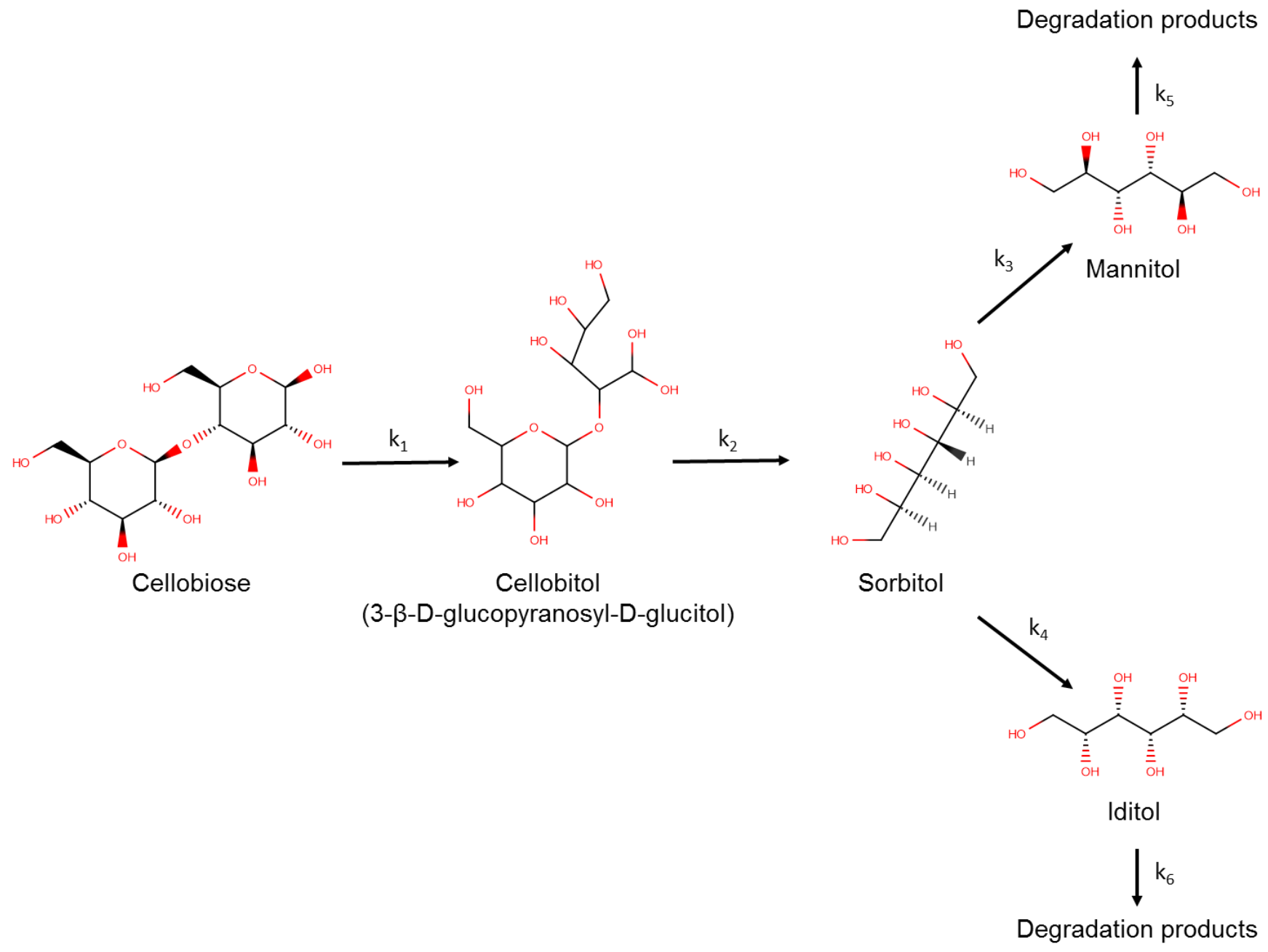

Scheme 1. Proposed reaction network for the catalytic conversion of cellobiose towards hexitols over Ru/Al-MCM-48. 